\title{
Exploring the concept of compressed air energy storage (CAES) in lined rock caverns at shallow depth:
}

\section{A modeling study of air tightness and energy balance}

\author{
Hyung-Mok Kim ${ }^{1}$, Jonny Rutqvist ${ }^{2}$, Dong-Woo Ryu ${ }^{1}$, Choon Sunwoo ${ }^{1}$, Won-Kyong Song ${ }^{1}$ \\ ${ }^{1}$ Korea Institute of Geoscience and Mineral Resources (KIGAM), Daejeon, 305-350 Korea \\ ${ }^{2}$ Lawrence Berkeley National Laboratory (LBNL), Berkeley, CA 94720 U.S.A.
}

September 28, 2011 


\section{ABSTRACT}

This paper presents a numerical modeling study of coupled thermodynamic, multiphase fluid flow and heat transport associated with underground compressed air energy storage (CAES) in lined rock caverns. Specifically, we explored the concept of using concrete lined caverns at a relatively shallow depth for which constructing and operational costs may be reduced if air tightness and stability can be assured. Our analysis showed that the key parameter to assure long-term air tightness in such a system was the permeability of both the concrete lining and the surrounding rock. The analysis also indicated that a concrete lining with a permeability of less than $1 \times 10^{-18} \mathrm{~m}^{2}$ would result in an acceptable air leakage rate of less than $1 \%$, with the operational pressure range between 5 and $8 \mathrm{MPa}$ at a depth of $100 \mathrm{~m}$. It was further noted that capillary retention properties and the initial liquid saturation of the lining were very important. Indeed, air leakage could be effectively prevented when the air-entry pressure of the concrete lining is higher than the operational air pressure and when the lining is kept moist at a relatively high liquid saturation. Our subsequent energy-balance analysis demonstrated that the energy loss for a daily compression and decompression cycle is governed by the air-pressure loss, as well as heat loss by conduction to the concrete liner and surrounding rock. For a sufficiently tight system, i.e., for a concrete permeability off less than $1 \times 10^{-18} \mathrm{~m}^{2}$, heat loss by heat conduction tends to become proportionally more important. However, the energy loss by heat conduction can be minimized by keeping the air-injection temperature of compressed air closer to the ambient temperature of the underground storage cavern. In such a case, almost all the heat loss during compression is gained back during subsequent decompression. Finally, our numerical simulation study showed that CAES in shallow rock caverns is feasible from a leakage and energy efficiency viewpoint. Our numerical approach and energy analysis will next be applied in designing and evaluating the performance of a planned full-scale pilot test of the proposed underground CAES concept.

Keywords: TOUGH-FLAC, compressed air energy storage (CAES), air tightness, energy balance, lined rock cavern (LRC) 


\section{Introduction}

Large scale energy storage systems (ESS) are becoming more important for energy load leveling, especially for widespread use of renewable energy. Wind and solar power are promising renewable energy sources, but other energy sources must be available when the wind is stagnant and solar energy is not available (i.e. at night).

Another important issue for renewable energy deployment is the physical distance between energy resources and energy demand. Long transmission distances from source to demand will result in significant additional cost for renewable energy. However, renewable energy equipped with ESS can overcome these problems of intermittency and high transmission cost, and can potentially provide a stable source of base load electricity.

A number of ESS technologies exist that are economical over various time scales, but only two technologies - CAES (compressed air energy storage) and PHS (pumped hydroelectric storage) - are cost-effective at large temporal scales (from several hours to days) and at a hundreds-of-MW power scale (Figure. 1). However, PHS has been known to have high capital costs and requires a difference in geodetic height.

CAES shares many of the same attractive qualities of PHS, such as high power capacity (50-300 MW), large energy storage capacity (2-50+hours), a quick start-up ( 9 min emergency start, 12 min normal operation), a long storage period (over a year), and relatively high efficiency (60-80\%) $[1,2,3]$. CAES can be more energy efficient and environmentally friendly during construction than PHS, but it also has disadvantages, such as finding a suitable site, the rather extended construction time, and the relatively high initial cost [4].

In underground CAES, off-peak or excess power is taken from the grid at low cost and used to compress and store air within an underground storage cavern. When needed, this high-pressure 
compressed air is then released, pre-heated in a recuperator, and expanded in a gas turbine to produce electricity during peak demand hours. For additional efficiency, the compressed air can be mixed with natural gas, then burned (as is often done in conventional generation) (Figure 2). Thus, greenhouse gas (GHG) emissions from a CAES plant are not zero; however, these GHG emissions are lower than those at electricity plants that burn fossil fuels.

The world's first commercial CAES facility, located in Huntorf, Germany, was commissioned in 1978 [5]. Two underground caverns in rock salt with a total storage volume of $310,000 \mathrm{~m}^{3}$ were excavated by solution mining. The cavern depth is more than $600 \mathrm{~m}$, which ensures the stability of the air for several months' storage, as well as guaranteeing a specified maximum pressure of about $10 \mathrm{MPa}$. The second commercial CAES facility was built at McIntosh, Alabama, in 1991 [4]. Several improvements over the Huntorf were incorporated, including a waste-heat recovery system that reduced fuel usage by $25 \%$. A storage cavern was located at more than $450 \mathrm{~m}$ underground in rock salt, with a storage volume at over $500,000 \mathrm{~m}^{3}$. Air storage pressure is about $7.4 \mathrm{MPa}$, and at full decompression, air pressure is about 4.5 MPa. Note that these two commercial CAES facilities were constructed in rock-salt formations that exist only in specific regions, and that these regions would not always be near an energy source or demand. Moreover, the CAES facilities were located relatively deep below the ground surface to achieve sufficient ambient fluid pressure, thereby preventing air leakage and assuring mechanical stability.

CAES in crystalline rock caverns has been studied in two feasibility tests in Japan [6, 7]. These facilities were also constructed at a depth of 200 to $500 \mathrm{~m}$; one was unlined, requiring surrounding groundwater pressure for air tightness, and the other was a lined old mine cavern.

The siting of CAES requires favorable geology as well as a suitable location near transmission lines and energy supplies. Potential sites for underground compressed air storage are grouped into three geologic categories: (1) rock caverns created by excavating hard rock formations, (2) salt caverns 
made by solution and dry mining of salt formations, and (3) porous-media reservoirs within waterbearing aquifers or depleted gas or oil fields [8]. Among these categories, note that salt formations can be found only at a limited number of locations, and that it is difficult to control air leakage and estimate the storage and production rate in aquifers due to high geologic uncertainty.

Excavated rock caverns would be more expensive to mine than salt caverns and naturally occurring reservoirs. However, excavation of new rock caverns provides more possibilities for site selection close to energy sources such as wind and solar power. Including the transmission line cost from energy source to demand, CAES in excavated caverns could be even more economical. Moreover, CAES in lined rock caverns using reinforced concrete and steel plates may be located at shallow depth and at significantly reduced construction costs, along with providing greater flexibility in site selection.

General requirements for underground rock caverns involved in CAES include stability, air tightness, acceptable surface subsidence, and (later on) an environmentally safe decommissioning and abandonment [9]. These general requirements are influenced by geomechanical design parameters such as cavern geometry and volume, cavern depth, operational pressure inside the cavern, distance between the caverns, allowable convergence of the excavated cavern, and operation pattern-in addition to the strength and permeability of the lining and surrounding rock mass. Groundwater table level and degree of saturation are also important for maximizing storage pressure while minimizing air leakage. Previous studies indicate that $\sim 30 \mathrm{~m}$ thick rock formations, with a compressive strength of 69-138 MPa and a conductivity of less than $2.0 \times 10^{-8} \mathrm{~m} / \mathrm{s}$ at a depth of $395-579 \mathrm{~m}$, are desirable for rock caverns [10].

Temperature changes are also expected during the compression and decompression cycle. From a thermodynamic perspective, Lux [9] concludes that increasing storage pressure increments of about 1 MPa could result in a $13^{\circ} \mathrm{C}$ temperature increase. Because of this potential temperature change and 
heat transfer to the concrete lining and surrounding rock mass, thermally induced stresses would be created that would influence the mechanical stability of a storage cavern. In addition to this thermalmechanical coupled deformation, high air pressure may significantly reduce the effective stress, which in turn may have important implications for mechanical stability and air leakage.

In this paper, we conduct a numerical modeling study of coupled thermodynamic, multiphase fluid flow and heat transport associated with underground compressed air energy storage (CAES) in lined rock caverns. Using the approach presented here, we carry out a parametric study to examine the influence of major design parameters on the air tightness of a concrete-lined rock cavern, such as the permeability, initial liquid saturation, and capillary pressure of the concrete lining and surrounding rock, the lining thickness, and cavern depth. Moreover, we thermodynamically investigate the influence of air injection temperature and thermal conductivity of the concrete lining on the heat loss through the lining, as well as the energy balance for such a CAES system. The findings of this work will ultimately be used in designing and evaluating the performance efficiency of a CAES pilot test in a lined hard rock cavern at a shallow depth being planned in Korea.

\section{Model Approach and Applicability}

In this analysis, we employ the numerical simulator TOUGH-FLAC $[11,12]$ for analyzing coupled thermodynamic, multiphase fluid flow and heat transport analysis, associated with CAES in underground excavations. TOUGH-FLAC has previously been applied to a wide range of problems involving coupled multiphase fluid flow, heat transport, and geomechanical processes, including geologic carbon sequestration [13,14], geothermal energy production from steam dominated geothermal reservoirs [15], and thermally driven coupled processes associated with underground excavations at temperatures above boiling [16].

\subsection{Principles of TOUGH-FLAC Coupled Analysis}

The principles of TOUGH-FLAC coupled analysis are shown in Figure 3. The simulator is based on 
linking two established codes, TOUGH2 [17] for multiphase flow and heat transfer, and FLAC ${ }^{3 \mathrm{D}}$ [18] for geomechanical analysis. In the coupled TOUGH-FLAC analysis, the two codes, TOUGH2 and $\mathrm{FLAC}^{3 \mathrm{D}}$, are linked using sequential execution and data transfer through nonlinear coupling functions. A TOUGH2 to FLAC ${ }^{3 \mathrm{D}}$ link takes multiphase pressures, saturation, and temperature from the TOUGH2 simulation and provides updated temperature and pore pressure to FLAC $^{3 \mathrm{D}}$ (Figure 3). After data transfer, FLAC ${ }^{3 \mathrm{D}}$ internally calculates thermal expansion and effective stress using a maximum pressure taken from the calculated pressures of the various phases-for example, air and water in this CAES simulation. The calculation is stepped forward in time using the transient thermalhydraulic (TH) analysis capability in TOUGH2, and at each time step or at the TOUGH2 Newton iteration level, a quasi-static mechanical (M) analysis is conducted with $\mathrm{FLAC}^{3 \mathrm{D}}$, to compute mechanical deformation from heat transfer and multiphase flow and to obtain stress-induced changes in porosity and intrinsic permeability. The resulting T-H-M coupled analysis can either be one-way sequential, meaning that only the TH impact on the mechanical deformation is calculated in FLAC3D, or it can be two-way sequential, meaning that stress-induced changes in porosity and permeability from FLAC3D are updated in the subsequent TOUGH2 simulation step using an iterative sequential process. In this preliminary calculation of the CAES system, we perform a one-way sequential coupled simulation.

\subsection{Model Setup of the Underground CAES System}

For this study, a 2-D model simulation is conducted for a vertical cross section of an underground CAES system. The numerical grid shown in Figure 4 contains all the vital components of rock, concrete lining, and an excavation disturbed zone (EDZ) that would have different material properties from the surrounding undisturbed host rock due to excavation-induced stress change. We explicitly represent the interior of the air-filled cavern as a medium of high porosity (1.0), high permeability, and mechanical softness. Using this approach, air can be injected and withdrawn, resulting in changes in air pressure, temperature, and stress exerted from the air pressure on the wall of the cavern. As shown in Figure 4, the air-filled cavern is represented by one row of numerical grid elements that in 
the model extends from a radius of $2 \mathrm{~m}$ to the cavern wall at a radius of $2.5 \mathrm{~m}$. However, in the TOUGH2 coupled thermodynamic, fluid flow and heat-transport analysis, the volume of these elements were increased by a factor of 2.78 , so that this row of elements adequately represents the entire air-filled cavern volume.

Table 1 presents a set of base case material properties for our analysis. In this simulation, we assign equivalent elastic properties for concrete, EDZ, and rock mass. The values are within the reasonable range for both concrete and crystalline rock and are adequate for this study, which is focused on air tightness, and energy balance. (A complete mechanical analysis is out of the scope of this paper.) The permeability of the concrete lining is significantly smaller than that of the rock mass, which is also reasonable considering the presence of natural fractures in the rock mass. Using the van-Genuchten model [19], the water-retention and relative permeability curves are taken from a previous study of water retention properties around a tunnel in fractured crystalline rock [20, 21]. In the base-case simulation, the retention properties of the concrete are here set to be equivalent to that of the rock.

In our base case simulation, initial pressure, temperature, and stress gradients are set for a cavern depth of $100 \mathrm{~m}$ and with the water table close to a ground surface. Initial temperature was set using a vertical gradient of $0.03{ }^{\circ} \mathrm{C} / \mathrm{m}$ and with a constant temperature of $10^{\circ} \mathrm{C}$ at the ground surface. At the depth of the cavern, this corresponds to an initial pressure and temperature of about $1 \mathrm{MPa}$ and $13^{\circ} \mathrm{C}$, respectively. During the simulated CAES operation, injection and withdrawal of air to and from the cavern is set to achieve a cavern pressure ranging between approximately 5 and $8 \mathrm{MPa}$. During construction and over long-term operation, the excess air pressure in the storage cavern and associated air leakage may lead to development of an unsaturated zone around the excavation. In our model simulations, the extent of the unsaturated zone was established in the model by running an initial long-term simulation at constant cavern pressure and temperature. For example, Figure 6 presents the distribution of gas saturation for a long-term simulation where the gas pressure in the cavern is kept at 6.25 $\mathrm{MPa}$, which is about average pressure for an operational pressure fluctuating between 5 to $8 \mathrm{MPa}$. 
After 1 year, the gas saturation in the lining is about $30 \%$, but after 15 years it has increased to about $60 \%$. Thus, under long-term overpressure in the cavern, the air-leakage tends to dry out the concrete lining over years of operation.

\subsection{Modeling of a Daily Compression and Decompression Cycle}

We first present an initial model simulation for one daily compression and decompression cycle, which will show the general thermodynamic and mechanical deformation response of the system. The daily cycle of air compression and withdrawal was simulated by first injecting air at a constant rate for 8 hours, storing it for an additional 4 hours, then producing at a constant rate for 4 hours, and finally waiting for another 8 hours till the start of a new compression cycle. Injection rates used in this model were calibrated to achieve a predefined storage air pressure of about $8 \mathrm{MPa}$ during the 8 -hour compression. Figure 5 shows the calculated evolution of pressure and temperature at 3 points (P1: within the cavern; P2: concrete lining; and P3: rock) with their locations shown in Figure 4. The results show some changes in fluid pressure and temperature in the concrete lining, whereas pressure and temperature do not change significantly in the rock a few meters from the excavation.

The calculated gas saturation is virtually constant during the compression-withdrawal cycle in both the concrete lining and surrounding rock, but a gas plume migrates into the rock as time elapses. Figure 6 demonstrates how gas saturation evolves in the near field of the cavern and in the lining. Figure 7 shows gas pressure and temperature contours. Note that significant pressure changes are confined within the cavern and concrete lining as the result of a relatively low concrete permeability. Most temperature changes occur within the cavern itself and on the inner surface of the concrete lining. In the rock outside the concrete lining, the pressure and temperature remain practically constant, but slightly elevated due to a long-term cavern overpressure and heat from compression.

Figure 8 presents the calculated radial displacements of the inner surface of the concrete liner. It shows that the air-filled cavern expands and contracts with a maximum magnitude of $0.3 \mathrm{~mm}$ (radius 
change). This is a very small displacement, leading to a volume change of about $5 \times 10^{-3} \mathrm{~m}^{3}$ that is negligible compared to the total cavern volume of $19.63 \mathrm{~m}^{3}$. The mechanical analysis also shows that tensile stress occurs in the concrete liner as a result of high internal cavern pressure during compression cycles. Such tensile stress could potentially lead to fracturing, which needs to be remediated with appropriate reinforcement.

This initial modeling demonstrated the applicability of TOUGH-FLAC to study coupled processes associated with underground CAES. Specifically, it was shown that the approach of explicitly including the air-filled interior of the excavation within the model as a highly porous, permeable, and mechanically soft material is a technically sound and practical approach. For modeling of a sitespecific CAES operation, site-specific geometry and material properties should be carefully selected. The current model, however, is adequate for conducting generic parameter studies to identify and determine the most important parameters for the thermodynamic performance of a CAES operation.

\section{Parametric Study of Air Tightness of the CAES system}

We conducted a parameter study to identify and determine the key parameters affecting the performance of the CAES system in terms of coupled thermodynamic multiphase fluid flow during multiple compression and decompression cycles. One of the key issues is air leakage out of the storage cavern into the surrounding formation, which would reduce the efficiency of the underground CAES system. In this type of system, the air leakage is a result of complex multiphase fluid-flow processes in the open cavern, concrete lining, and surrounding rock mass. In this section, we introduce the results of a mass-balance analysis and rates of air leakage using thermodynamic, multiphase fluid flow and heat simulations provided by TOUGH-FLAC, but without considering geomechanical changes.

\subsection{Basic Air-Mass Balance}

Using the material parameters in Table 1, we assess the leakage rate for an assumed depth of $100 \mathrm{~m}$ 
and with the water table close to the ground surface. The air-injection and withdrawal rates are set to obtain an operation pressure ranging between 5 to $8 \mathrm{MPa}$, which is significantly higher than the ambient hydrostatic water pressure of about $1 \mathrm{MPa}$. Thus, even without any daily pressure fluctuations, the cavern is overpressurized compared to the ambient hydrostatic pressure, and therefore, continuous air leakage would occur. The leakage rate may then be further affected by the pressure cycles. In the simulations, air is compressed during the 8 hour compression phase by injecting air at a rate of $2.2 \times 10^{-2} \mathrm{~kg} / \mathrm{s}$ per meter of cavern. The 4 hour decompression phase is simulated by releasing the pressure at a rate of $4.4 \times 10^{-2} \mathrm{~kg} / \mathrm{s}$.

Assuming an ideal gas, the total mass stored in a storage cavern at a certain pressure and temperature can be estimated from the ideal gas law as:

$$
m=\frac{P V_{\text {cavern }}}{R_{\text {air }} T}
$$

where $m$ is mass of gas $(\mathrm{kg}), P$ is absolute pressure $(\mathrm{Pa})$ within the cavern, $V_{\text {cavern }}$ is cavern volume $\left(\mathrm{m}^{3}\right), R_{\text {air }}$ is the specific gas constant for air $(=286.9 \mathrm{~J} / \mathrm{kg} \mathrm{K})$, and $T$ is absolute temperature ${ }^{\circ} \mathrm{K}$. The total volume of the open cavern inside the concrete lining remains is considered constant during the compression and decompression cycles, and is calculated as $\pi \times 2.5^{2} \approx 19.63 \mathrm{~m}^{3}$ per meter along the cavern axis. The constant volume assumption is justified by the very small changes in radial displacements of the cavern as shown in Figure 8.

During the compression and decompression cycles, pressure and temperature within the cavern vary nonlinearly with time, and with the air mass lost from the cavern; a leakage rate can be determined using Equation (1) according to:

$$
\Delta m=m_{1}-m_{2}=\frac{V_{\text {cavern }}}{R_{\text {air }}}\left(\frac{P_{1}}{T_{1}}-\frac{P_{2}}{T_{2}}\right)
$$

where subscripts 1 and 2 indicate initial and later state, respectively. 


\subsection{Case of Tight Concrete Lining}

Figure 9 represents the results of a longer term simulation at a constant cavern pressure of $6.25 \mathrm{MPa}$, which approximately corresponds to the average cavern pressure over a daily compression and decompression cycle. The $6.25 \mathrm{MPa}$ is significantly higher than the ambient formation pressure of 1 $\mathrm{MPa}$, and therefore air slowly leaks out and desaturates the concrete lining and the rock. Figure 9 shows the evolution of the leakage rate (or the injection rate to keep the pressure in the cavern constant) as well as the evolution of gas saturation. The figure indicates that the leakage rate increases over the years, caused by a slowly expanding gas plume around the cavern. The expanding gas plume provides an increased gas saturation and gas relative permeability, resulting in a gradual increase in leakage rate. However, in this case, a very tight concrete lining with $1 \times 10^{-20} \mathrm{~m}^{2}$ permeability is assumed. which results in a very small leakage rate. For example, after 15 years, the leakage rate is about $1.0 \times 10^{-6} \mathrm{~kg} / \mathrm{s}$, which corresponds to about $8.6 \times 10^{-2} \mathrm{~kg} /$ day.

In a system in which compressed air is stored with compression and decompression cycles within the range of 5 to $8 \mathrm{MPa}$, a representative leakage percentage should probably be calculated relative to the minimum pressure level of $5 \mathrm{MPa}$. The incremental air mass stored at $6.25 \mathrm{MPa}$, relative to a minimum pressure of $5 \mathrm{MPa}$, can be estimated as $m=298.9 \mathrm{~kg}$ and the corresponding daily leakage can be estimated as $\left(8.6 \times 10^{-2} / 298.9\right) \times 100=3.0 \times 10^{-2} \%$, which is still a negligible amount from a CAES storage efficiency perspective.

Figure 10 displays the results from simulating 10 daily compression/decompression cycles using the material parameters listed in Table 1. Initial thermodynamic and fluid-flow conditions for this simulation correspond to the conditions at 15 years of the previous constant pressure simulation (Figure 9). At this stage, the gas saturation in the concrete lining has increased to about $60 \%$. The results in Figure 10 show that the cavern pressure is fully recovered after each cycle, which can be expected, considering the negligible leakage rate estimated above (about $1.0 \times 10^{-6} \mathrm{~kg} / \mathrm{s}$ ). Moreover, the temperature fluctuates roughly between 6 and $20^{\circ} \mathrm{C}$, whereas the saturation remains practically 
constant. In this case, air was injected at a temperature of $21^{\circ} \mathrm{C}$, which is achieved by injecting air with a prescribed constant specific enthalpy of air mass in TOUGH2 [17].

\subsection{Case of Leaky Concrete Lining and Permeable Rock}

In this case, the permeability of the concrete lining and the rock is increased to $1 \times 10^{-16} \mathrm{~m}^{2}$, leading to a leaky system in which the pressure would decline after every daily cycle. Figure 11 represents the initial constant-pressure simulation for reproducing initial conditions, leading up to a gas saturation of about 60 to $70 \%$ after a few years. Again, the leakage rate increases with time as the gas plume expands in the rock mass and the gas relative permeability increases. The leakage rate is $1.04 \times 10^{-3}$ $\mathrm{kg} / \mathrm{s}$, which corresponds to $89.9 \mathrm{~kg} /$ day.

Figure 12 presents the results of 10 daily compression cycles using injection rates of $22 \times 10^{-3} \mathrm{~kg} / \mathrm{s}$ and decompression phases using a release rate of $44 \times 10^{-3} \mathrm{~kg} / \mathrm{s}$. During the 10 cycles, the average pressure decreases from about $6 \mathrm{MPa}$ to $4.5 \mathrm{MPa}$ at the end of the $10^{\text {th }}$ cycle. Figure 12 also shows that the pressure fluctuates synchronously over the entire system, including cavern, concrete lining, and surrounding rock. Interestingly, the gas saturation does not display any visible fluctuations, but remains constant at about 0.7 to 0.8 in both the concrete lining and rock.

Figure 13 presents the results of a shut-in test in which the gas flow to the cavern is cut off. The cavern pressure decreases with time as air leaks through the concrete liner, decreasing nonlinearly because of a progressively reduced pressure gradient. The leakage rate in the first 24 hours is estimated using Equation (2), with pressure and temperature values extracted from the numerical simulation results. The initial pressure and temperature in the cavern is $P_{1}=6.25 \mathrm{MPa}$ and $T_{1}=$ $286.15^{\circ} \mathrm{K}$. After 24 hours, pressure and temperature are $P_{2}=5.91 \mathrm{MPa}$ and $T_{2}=285.58{ }^{\circ} \mathrm{K}$. Using these values, we calculate a leakage rate of about $78 \mathrm{~kg} /$ day — an average rate for the first 24 hours. The initial leakage rate, i.e., for the first hour, corresponds to a leakage rate of about $90 \mathrm{~kg} / \mathrm{day}$, in agreement with the results of the abovementioned constant pressure injection test shown in Figure 12. 
A leakage rate of $78 \mathrm{~kg} /$ day corresponds to a leakage percentage of $78 / 298.9 \times 100=26 \%$ with the mass loss relative to a $5 \mathrm{MPa}$ minimum pressure.

Figure 14 shows the solution for an injection schedule that maintains a constant cavern pressure during the entire 10 cycle simulation. This was achieved by increasing the injection rate during the 8hour-long compression from $22 \times 10^{-3} \mathrm{~kg} / \mathrm{s}$ to $25.1 \times 10^{-3} \mathrm{~kg} / \mathrm{s}$. Again, these values are the rates per unit length of cavern whereas the halves of these values are the actual inputs in the half-symmetric model. The required rate increase during the 8-hour-long injection phase can be calculated from the final leakage rate of $1.04 \times 10^{-3} \mathrm{~kg} / \mathrm{s}(89.9 \mathrm{~kg} /$ day $)$ that was obtained from the 3-year constant pressure injection shown in Figure 11. The required rate is calculated as $(22+1.04 \times 24 / 8) \times 10^{-3}=25.1 \times 10^{-3}$ $\mathrm{kg} / \mathrm{s}$. In such a case, we may define the leakage percentage as $((25.1-22) / 25.1) \times 100=12 \%$. Thus, $12 \%$ of the injected air mass is lost during each daily cycle.

The results for the leaky system demonstrate how leakage rate can be determined in practice during a CAES operation. The results showed that $12 \%$ of the total mass injected during the compression cycle would not be recovered during the decompression. This number could also be estimated either from a constant pressure injection or shut-in test. In both cases, the leakage rate was estimated to be about 90 $\mathrm{kg} /$ day. The total mass stored during an 8 hour compression cycle may be determined from the injection rate as $25.1 \times 10^{-3} \times 3600 \times 8=722.9 \mathrm{~kg}$, or, alternatively, the total mass could also be estimated using Equation (2), using monitored pressure and temperature changes within the cavern. The daily leakage can then be estimated as $90 / 722.9=12 \%$.

Figure 15 presents the evolution of leakage rate and daily leakage percentage for various combinations of lining and rock permeability. The results shows that leakage of less than $1 \%$ would be achieved if permeability of the concrete lining were less than $1 \times 10^{-18} \mathrm{~m}^{2}$, even if the permeability of the rock were as high as $1 \times 10^{-15} \mathrm{~m}^{2}$. A less than $1 \%$ leakage rate is also achieved if the rock mass permeability were less than $1 \times 10^{-17} \mathrm{~m}^{2}$, even with a comparatively permeable concrete lining. 


\subsection{Leakage Rates for Different Initial Gas Saturation of the Concrete}

In our previous constant pressure simulations shown in Figures 9 and 11, we can see that the leakage rate increases with increasing gas saturation (and decreasing water saturation) in the concrete lining. In this section, we present a more detailed examination of what impact the gas saturation in the concrete lining might have on the leakage rates during the 10 cycle CAES operation. Table 2 summarizes the result of our analysis, conducted for a leaky system in which the concrete lining and the rock is set to $1 \times 10^{-16} \mathrm{~m}^{2}$. From our previous simulations presented in Figures 12 through 14 , we calculated a daily leakage of $12 \%$ when the gas saturation in the concrete lining was $74 \%$. In Table 2 , we compare this to another case in which the gas saturation in the concrete lining is $29 \%$. In such a case, the constant rate injection is $6.38 \times 10^{-5} \mathrm{~kg} / \mathrm{s}(5.51 \mathrm{~kg} /$ day $)$, leading to a first estimation of the daily leakage percentage as $5.51 / 722.9 \times 100 \approx 0.8 \%$. This estimate was verified by running the simulation with an increased injection rate during the 8-hour-long compression from $22 \times 10^{-3} \mathrm{~kg} / \mathrm{s}$ to $22.19 \times 10^{-3} \mathrm{~kg} / \mathrm{s}$. This increased injection rate was calculated as $(22+0.0638 \times 24 / 8) \times 10^{-3}=22.19 \times 10^{-3}$ $\mathrm{kg} / \mathrm{s}$. Again, we can calculate the daily leakage percentage from this result as $((22.19-22) / 22.19) \times 100$ $\approx 0.8 \%$.

These results show that the saturation in the concrete has a significant impact on the CAES system air tightness. This is further illustrated in Figure 16, which presents the leakage rate and daily leakage percentage as a function of gas saturation in the lining.

\subsection{Leakage Rates for Different Water Retention Properties of the Concrete}

In the base case simulations, the capillary pressure and relative permeability functions used for the concrete lining were identical to those of the surrounding rock using van Genuchten's capillary pressure function [19], with the parameter $P_{0}$ set to $1.47 \mathrm{MPa}$. The $P_{0}$ parameter, related to the airentry pressure, is therefore important for capillary trapping. For the assumed CAES system, the gas 
pressure within the cavern varies from 5 to $8 \mathrm{MPa}$, far exceeding $P_{0}$ and resulting in no significant capillary trapping. However, a literature review of capillary-pressure measurements in concrete indicates that $P_{0}$ could vary widely, and in some cases values of several tens of MPa have been measured. For example, Navarro et al. [22] fitted the van Genuchten model to their experimental data with $P_{0}=34.6 \mathrm{MPa}$ and $\mathrm{m}=0.63$.

We conducted a sensitivity study varying $P_{0}$ between extreme values ranging from 0.5 to $34.6 \mathrm{MPa}$. Figure 17 shows the evolution of daily leakage percentage when the lining permeability was set to $1 \times 10^{-18} \mathrm{~m}^{2}$ and rock permeability to $1 \times 10^{-17} \mathrm{~m}^{2}$. The results show that the leakage rate is highly sensitive to changes in $P_{0}$. For $P_{0}=1.47 \mathrm{MPa}$ and $0.5 \mathrm{MPa}$, the results indicate no significant capillary-trapping or relative permeability effects, which means that the leakage rate in those cases is limited by the low lining permeability of $1 \times 10^{-18} \mathrm{~m}^{2}$. However, for a $P_{0}$ of 5 and $10 \mathrm{MPa}$, the leakage rate is reduced more than an order of magnitude, and for $P_{0}=34.6 \mathrm{MPa}$, virtually no air leakage occurs because the gas pressure in the cavern is far from exceeding the air-entry pressure of the lining.

\subsection{Leakage rates for different cavern depth on leakage}

Increasing the cavern depth from $100 \mathrm{~m}$ to $500 \mathrm{~m}$ reduced the leakage rate by about 2 orders of magnitude. This was true for both the tight-lining system $\left(k_{\text {lining }}=1 \times 10^{-20} \mathrm{~m}^{2}\right.$ and $\left.k_{\text {rock }}=1 \times 10^{-17} \mathrm{~m}^{2}\right)$ and the leaky system $\left(k_{\text {lining }}=1 \times 10^{-16} \mathrm{~m}^{2}\right.$ and $\left.k_{\text {rock }}=1 \times 10^{-16} \mathrm{~m}^{2}\right)$. Table 3 shows an approximately 2orders-of-magnitude reduction in leakage rate compared to the corresponding results for a depth of $100 \mathrm{~m}$ in Figures 9 and 11. The 2-orders-of-magnitude reduction can be explained by reduced relative permeability in the lining, as well as reduced pressure gradient resulting from the increased hydrostatic liquid pressure with depth. The gas pressure gradient becomes smaller because the capillary pressure, which depends on the difference between the injected gas pressure and the ambient hydrostatic liquid pressure, is smaller. Thus, at depth the lining will be kept at a higher moisture content, which tends to reduce the leakage rate. 


\section{Energy Balance Analysis of the CAES System}

We present an energy-balance analysis of the CAES operation in the lined cavern, in order to understand the energy loss and the relative contributions from air leakage and heat loss to the overall energy budget. This analysis was inspired by the analytical work of Nakata et al. [23], who evaluated the thermodynamic performance of a CAES pilot test. In our study, we applied the energy-balance analysis over multiple CAES compression cycles, using the output results from the TOUGH-FLAC simulations.

\subsection{Basic Energy Balance}

From the first law of thermodynamics, the change in total energy stored in the CAES underground cavern $\left(\Delta E_{\mathrm{s}}\right)$ can be expressed as the summation of the change in internal energy $(\Delta E)$, the work done $(\Delta W)$ by injected compressed air, and the sum of outflows by production, air leakage, and heat $\operatorname{transfer}(\Delta Q)$ :

$$
\Delta E_{s}=\Delta E+\Delta W+\Delta Q
$$

The change in internal energy within the underground storage cavern and work done by the compressed air is the difference between those quantities of transported (injected or produced) compressed air and leaking air, so that Equation (3) can be rewritten as:

$$
\Delta E_{s}=\left(\Delta E_{m}-\Delta E_{l}\right)+\left(\Delta W_{m}-\Delta W_{l}\right)+\Delta Q=\left(\Delta E_{m}+\Delta W_{m}\right)-\left(\Delta E_{l}+\Delta W_{l}\right)+\Delta Q
$$

where $\Delta E_{m}(\mathrm{~J} / \mathrm{s})$ is the rate of change in internal energy by air movement during compression and decompression, $\Delta E_{l}(\mathrm{~J} / \mathrm{s})$ is the internal energy loss by air leakage, $\Delta W_{m}(\mathrm{~J} / \mathrm{s})$ is the work done by the injected/produced air movement during compression and decompression, and $\Delta W_{l}(\mathrm{~J} / \mathrm{s})$ is the work done by leaking air. The term "air movement" is here related to the movement of air in or out of the cavern through pipeline well connected with surface facilities, whereas "leakage" refers to air loss from the air-filled cavern across the wall surface of the concrete liner.

Since the volume change in the underground cavern is restricted and very small, the internal energy is 
determined by air-mass flow, specific heat, and air temperature. The work done by the air movement and leakage of the stored air is the product of pressure $(P)$ and volume $(V)$ changes in the air, which results in the function of air mass flow and temperature by the ideal gas law. Heat exchange between the air filled cavern and the concrete lining occurs by two distinct mechanisms: heat conduction $\left(Q_{c}\right)$ and advection $\left(Q_{a}\right)$ with air flow.

$$
\begin{gathered}
\Delta E=C_{\text {air }} \cdot T \cdot m \\
\Delta W=P \cdot V=R_{\text {air }} \cdot T \cdot m \\
\Delta Q=\Delta Q_{c}+\Delta Q_{a}
\end{gathered}
$$

where $m(\mathrm{~kg} / \mathrm{s})$ is the air mass flow, $C_{\text {air }}\left(\mathrm{J} / \mathrm{kg}{ }^{\circ} \mathrm{K}\right)$ is the specific heat at the constant volume, $T\left({ }^{\circ} \mathrm{K}\right)$ is the temperature, $P(\mathrm{~Pa})$ is pressure, $V\left(\mathrm{~m}^{3}\right)$ is volume, $\Delta Q_{c}(\mathrm{~J} / \mathrm{s})$ is heat conduction rate, and $\Delta Q_{a}$ $(\mathrm{J} / \mathrm{s})$ is heat advection rate.

Then Equation (4) can be written as

$$
C_{\text {air }} T_{s} \Delta m_{s}=\frac{C_{a i r}}{R} V_{s} \frac{\partial P_{s}}{\partial t}=\left(C_{\text {air }}+R_{\text {air }}\right) T_{m} m_{m}-\left(C_{\text {air }}+R_{\text {air }}\right) T_{l} m_{l}+\left(\Delta Q_{c}+\Delta Q_{a}\right)
$$

where $\Delta m_{s}$ is the rate of change of stored air mass, $m_{m}$ and $m_{l}$ are the mass flows $(\mathrm{kg} / \mathrm{s})$ by air movement due to injection and production as well as air leakage, and $T_{s}, T_{m}$, and $T_{l}$ are the temperatures $\left({ }^{\circ} \mathrm{K}\right)$ of stored air, injected/produced, and leaking air, respectively. Here, $V_{s}$ is the volume of stored air, equal to cavern volume. $T_{m}$ is equal to the injection temperature $\left(21^{\circ} \mathrm{C}=\right.$ $294.15^{\circ} \mathrm{K}$ ) during the compression, and equal to cavern temperature, i.e., temperature of stored air $T_{s}$ during decompression. The temperature of leaking air $\left(T_{l}\right)$ is taken to be equal to the temperature of stored air $\left(T_{s}\right)$.

\subsection{Energy Balance Analysis in Cases of Tight and Leaky Lining}


The energy balance during 10 daily cycles of compression and decompression were calculated, and the results are shown in Figures 19 and 20. We directly use TOUGH-FLAC simulation results to determine the values of each term in Equation (6), including the rate of mass change $\left(\Delta m_{s}\right)$, the storage pressure $\left(P_{s}\right)$ and temperature $\left(T_{s}\right)$ of air, mass flow rate of air movement $\left(m_{m}\right)$, and leakage $\left(m_{l}\right)$. Figure 18 and 19 (a) to (e) present the calculation results of each term in Equation (6) for the tight and leaky concrete lining cases, respectively. The rates of change in the cavern for air injection and production during the compression and decompression phases (which correspond to the left-hand side of Equation (6)) are shown in Figure 18 and 19a. Note that the rate of change is decreasing during the compression phase (Figure 19a) because of significant air leakage in the leaky lining case and consequent pressure decrease within the storage cavern. Again, the injection air temperature was set to $21^{\circ} \mathrm{C}$ during the compression phase, whereas the air temperature in the cavern was used for the calculations of energy exchange by air flow during other phases (Figure 18 and 19b).

Figure 18 and $19 \mathrm{c}$ show the energy-loss rate due to air leakage and correspond to the $2^{\text {nd }}$ term of the right-hand side of Equation (6). Note that the energy-loss rate from leaking air decreases in the leaky lining case (Figure 19c), because the pressure gradient from the lining becomes smaller when the pressure of stored air decreases. The energy-loss rate due to heat transfer, including both heat conduction through the lining and advection due to air leakage (which corresponds to the $3^{\text {rd }}$ term of the right-hand side of Equation (6)) are shown in Figure 18 and 19d. The energy loss during the compression phase in the tight lining case is kept constant, but decreases in the leaky case since in such a case temperature gradient is less significant (Figure 19k). The hatched area in Figure 19 and $20 \mathrm{e}$ are the energy rate of injection and production minus the rate of energy change in stored air, which corresponds to the energy loss including both air leakage (Figures 18 and 19c) and heat transfer (Figures 18 and 19d).

For a more quantitative energy balance analysis, time integrated values of each term in Equation (6) 
of the $5^{\text {th }}$ cycle were calculated (Figure 18 and $19 \mathrm{f}$ through o) and summarized in Table 4 . In the calculation, shut-in phases in between compression and decompression are included, so that both compression and decompression phases are 12-hour periods. In the tight lining case, the energy loss through heat conduction is greater than that of air leakage by 2 orders of magnitude, and it is as much as $28 \%$ of the total injected energy during compression. Negative energy loss during the decompression phase in Table 4 means an energy gain from the surroundings. This energy gain is energy recovered through heat conduction from the concrete lining to the stored air during the decompression phase of the tight lining case; it is as much as $24 \%$ of total injected energy. Thus, $4 \%$ of injected energy is lost during this daily cycle. In the leaky lining case, the energy loss by heat conduction is still greater than that of air leakage, but both are within the same order of magnitude. Due to the energy loss by air leakage, total energy loss during the compression phase in the leaky lining system is as much as $36 \%$ of total injected energy, and ultimately $10 \%$ of the total injected energy is lost during the cycle. We find that heat conduction between the stored air and the concrete lining plays a major role in the CAES energy balance and is even more significant than air leakage in the leaky lining system. However, it should be noted that most heat loss to the liner during compression is regained during subsequent decompression.

\subsection{Energy Balance for Different Injection Temperature and Thermal Conductivity of the}

\section{Lining}

Injection temperature and thermal conductivity of the concrete lining are important factors for the evolution of temperature during compression and decompression. The maximum and minimum temperature achieved during compression depends on the temperature of the injected air, as well as the heating of the air caused by the compression itself and the rate of heat exchange between the cavern and the lining. In the base case simulation, an injection temperature of $21^{\circ} \mathrm{C}$ was set by injecting air with a constant specific enthalpy of air mass.

We investigated the influence of injection temperature on energy balance; the results are summarized 
in Table 5. If we reduce the injection temperature close to the ambient temperature of $13^{\circ} \mathrm{C}$, the heat loss through the lining as well as total energy loss can be reduced to $1 \%$ of the total energy injected into the cavern during the compression phase. As the injection temperature increases, the heat loss becomes more significant, and the total energy loss increases to $11 \%$ through the cycle at the injection temperature of $46^{\circ} \mathrm{C}$.

In the base-case simulation, the thermal conductivity of the lining and surrounding rock was set to 3.0 $\mathrm{J} / \mathrm{s} \mathrm{m}^{\circ} \mathrm{K}$. Considering various types of concrete and other lining materials that can be replaced with the concrete as an alternative, we changed the thermal conductivity of the lining and examined the energy balance. We found that we could not lower the thermal conductivity of the lining to less than $2.5 \mathrm{~J} / \mathrm{s} \mathrm{m}{ }^{\circ} \mathrm{K}$, since the temperature within the cavern drops below $0^{\circ} \mathrm{C}$, using our base case model with an injection temperature of $21^{\circ} \mathrm{C}$ at an ambient rock temperature of $13^{\circ} \mathrm{C}$. The results for a thermal conductivity of $2.5 \mathrm{~J} / \mathrm{s} \mathrm{m}{ }^{\circ} \mathrm{K}$ were almost identical with the base-case model results. When we increase the thermal conductivity of the lining by 10 times to $30 \mathrm{~J} / \mathrm{s} \mathrm{m}{ }^{\circ} \mathrm{K}$, which corresponds to the value of steel lining, the energy balance is unchanged at a total energy loss of $4 \%$, even though the magnitude of heat inflow and outflow rises according to high thermal conductivity, compared to our base case. This shows that any heat loss to the liner during compression is regained during and after the subsequent decompression, through efficient heat exchange between the cavern air and the concrete liner. Moreover, outside the concrete liner, the rock mass still has a low thermal conductivity, and therefore the entire heat loss from the cavern is stored in the concrete liner and then recovered during decompression. Thus, it appears that insulation through lowering the thermal conductivity of lining is not necessarily required in an underground storage cavern, in terms of energy balance.

\section{Conclusions and Discussion}

We conducted a numerical modeling study of coupled thermodynamic, multiphase fluid flow and heat transport associated with underground compressed air energy storage (CAES) in lined rock caverns. Specifically, we explored the possibility of using concrete lined caverns at a relatively shallow depth, 
such that constructing and operational costs may be reduced if air tightness and stability can be assured.

Our analysis showed that the key parameter to assure the long-term air tightness of such a system was the permeability, both of the concrete lining and the surrounding rock. Our analysis indicated that a concrete lining with a permeability of less than $1 \times 10^{-18} \mathrm{~m}^{2}$ would result in an acceptable air leakage rate of less than $1 \%$, with the operational pressure range between 5 and $8 \mathrm{MPa}$ at a depth of $100 \mathrm{~m}$. We also found that the capillary retention properties and initial gas saturation of the lining could be a very significant parameter, and air leakage could be effectively prevented if the air-entry pressure of the concrete lining were higher than the operational air pressure, and the lining were kept at a higher moisture content.

Our subsequent energy-balance analysis demonstrated that the energy loss for a daily compression and decompression cycle depends on the air-pressure loss and well as heat loss by conduction to the concrete liner and surrounding rock. For a sufficiently tight system, i.e., for a lining permeability less than $1 \times 10^{-18} \mathrm{~m}^{2}$, heat loss by heat conduction tends to become proportionally more important. However, the energy loss by heat conduction can be minimized by keeping the air-injection temperature of compressed air closer to the ambient temperature of the underground storage cavern. In such a case, almost all the heat loss during compression is gained back during subsequent decompression.

The numerical analysis and approach applied in this study show that CAES in a shallow rock cavern is feasible from a leakage and energy-efficiency perspective. For a tight system with an injection temperature close to ambient rock temperature, the energy loss was limited to $1 \%$. The total energy stored during the daily compression cycle is about $180 \mathrm{MJ}$ per meter drift. Thus, over a 24-hour period, we can store about 2,000 W per meter drift. However, note that our analysis is focused on air tightness and energy balance of the underground cavern, whereas additional energy transfer will also 
occur during the compression and cooling of the air at the ground surface facility. For example, in our analysis we considered injection of compressed air into the cavern at a constant temperature of $21^{\circ} \mathrm{C}$, which will require cooling during compression at the ground surface facility. Thus, our results are related to the thermodynamic performance of the underground cavern, which is different from the overall efficiency of a CAES system.

Finally, our simulation results indicate that tensile stresses develop in the concrete lining during high pressure compression cycles. Tensile stress in the lining may significantly impact the air tightness, especially if fracturing occurs. The impact of the tensile stress in lining is currently being examined in terms of air tightness as well as the mechanical stability of underground CAES at shallow depths. In future CAES systems at shallow depth, high strength concrete and adequate reinforcement will be required.

\section{Acknowledgments}

This research was supported by the Basic Research Project of the Korea Institute of Geoscience and Mineral Resources (KIGAM, GP2009-019) funded by the Ministry of Knowledge and Economy of Korea, and funding from KIGAM for Jonny Rutqvist and Berkeley Lab was provided through the U.S. Department of Energy Contract No. DE-AC02-05CH11231. Editorial review by Dan Hawkes at Berkeley Lab is greatly appreciated.

\section{References}

[1] H. Chen, Y. Cong, W. Yang, C. Tan, Y. Li, and Y. Ding, Progress in electrical energy storage system: a critical review, Prog. Nat. Sci. 19 (2009), pp. 291-312.

[2] I. Hadjipaschalis, A. Poullikkas, and V. Efthimiou, Overview of current and future energy storage technologies for electric power applications, Renewable Sustainable Energy Rev. 13 (2009), pp.15131522.

[3] H. Ibrahim, R. Younes, A. Illinca, M. Dimitrova, and J. Perron, Study and design of a hybrid wind- 
diesel-compressed air energy storage system for remote areas, Applied Energy 87 (2010), pp.174962

[4] D. Pepper, Utility Power Storage Technologies, BCC Research, 2008.

[5] F. Crotogino, K.U. Mohmeyer, and R. Scharf, Huntroft CAES: More than 20 years of successful operation. Spring 2001 Meeting. Orlando, Florida, USA. 15-18 April 2001

[6] T. Shidahara, K. Nakagawa, Y. Ikegawa, H. Suenaga, and Y. Miyamoto, Demonstration study for the compressed air energy storage technology by the hydraulic confining method at the Kamioka testing site. CRIEPI Report U1024, 2001 (in Japanese).

[7] T. Shinohara. Y. Aida, H. Kawakami, and K. Fukuda, High compressed air storage in rock bed 450 meter down below the ground Kami-sunagawa pilot plant construction work, Tunnels and Underground 32 (2001), pp. 495-503 (in Japanese).

[8] A. J. Giramonti, R.D. Lessard, W.A. Blecher, and E.B. Smith, Conceptual design of compressed air energy storage electric power systems, Applied Energy 4 (1978), pp.231-239.

[9] K. H. Lux, Design of salt caverns for the storage of natural gas, crude oil and compressed air: Geomechanical aspects of construction, operation and abandonment, Underground gas storage: Worldwide Experiences and Future Development in the UK and Europe, MPG Books Ltd., Bodmin, UK, 2010.

[10] B.R. Mehta, and D. Spencer, Siting compressed-air energy plants, Tunnelling and Underground Space Technology 3 (1988), pp.295-299.

[11] J. Rutqvist, Y.S. Wu,C.F. Tsang, and G. Bodvarsson, A Modeling approach for analysis of coupled multiphase fluid flow, heat transfer, and deformation in fractured porous rock, International Journal of Rock Mechanics and Mining Science 39 (2002), pp.429-442.

[12] J. Rutqvist. Status of the TOUGH-FLAC simulator and recent applications related to coupled fluid flow and crustal deformations, Computers and Geosciences, in press (2010), doi:10.1016/j.cageo.2010.08.006

[13] J. Rutqvist, J.T. Birkholzer, C.F. Tsang, Coupled Reservoir-Geomechanical Analysis of the Potential for Tensile and Shear Failure Associated with CO2 Injection in Multilayered Reservoir- 
Caprock Systems, International Journal of Rock Mechanics and Mining Science 45 (2008), pp.132143.

[14] F. Cappa, and J. Rutqvist, Modeling of coupled deformation and permeability evolution during fault reactivation induced by deep underground injection of $\mathrm{CO} 2$, International Journal of Greenhouse Gas Control (2010), doi:10.1016/j.ijggc.2010.08.005

[15] J. Rutqvist, and C.M. Oldenburg, Analysis of injection-induced micro-earthquakes in a geothermal steam reservoir, Geysers Geothermal Field, California. Proceedings of the 42th U.S. Rock Mechanics Symposium, San Francisco, California, USA, June 29-July 2, 2008: American Rock Mechanics Association ARMA, Paper No. 151.

[16] J. Rutqvist, B. Freifeld, K.B. Min, D. Elsworth, and Y. Tsang, Analysis of thermally induced changes in fractured rock permeability during eight years of heating and cooling at the Yucca Mountain Drift Scale Test, International Journal of Rock Mechanics and Mining Science 45 (2008), pp.1373-1389.

[17] K. Pruess, C. Oldenburg, and G. Moridis, TOUGH2 User's Guide Version 2.0, LBNL-43134, 1999.

[18] Itasca, FLAC3D, Fast Lagrangian Analysis of Continua in 3 Dimensions, Version 4.0. Minneapolis, Minnesota, Itasca Consulting Group, pp.438. 2009.

[19] M.T. van Genuchten, A closed-form equation for predicting the hydraulic conductivity of unsaturated soils, Soil Sci Soc Am J 44 (1980), pp.892-898.

[20] S. Finsterle and K. Pruess, Solving the estimation-identification problem in two-phase flow modeling, Water Resources Research 31 (1995), pp.913-924.

[21] E.E. Alonso, J. Alcoverro et al., (26 co-authors), The FEBEX Bechmark test. Case Definition and comparison of modelling approaches, International Journal of Rock Mechanics and Mining Sciences 42 (2005), pp.611-638.

[22] V. Navarro, A. Yustres, L. Cea, M. Candel, R. Juncosa, and J. Delgado, Characterization of the water flow through concrete based on parameter estimation from infiltration tests, Cement and Concrete Research 36 (2006), pp.1575-82. 
[23] M. Nakata, H. Yamachi, A. Nakayama, S. Sakurai, and T. Shidahara, Thermo-dynamical approach to compressed air energy storage system. Proceedings of Japan Society of Civil Engineers (JSCE) 610 (1998), pp.31-42 (in Japanese).

\section{Table Captions}

Table 1. Material properties used as a base case for modeling of CAES in a lined rock cavern.

Table 2. :Leakage rate for different initial saturation of concrete lining and rock.

Table 3. Leakage rate for different cavern depth.

Table 4. Calculated time integrated energy balance term in the $5^{\text {th }}$ cycle of compression and decompression.

Table 5. Calculated time integrated energy balance term in the $5^{\text {th }}$ cycle of compression and decompression for different injection temperature and thermal conductivity of lining.

\section{Figure Captions}

Figure 1. Distribution of ESS techniques as a function of their field of application (http://www.electricitystorage.org/ESA/technologies/, accessed 2011.1).

Figure 2. Components of a CAES system (modified from http://gridflexenergy.com/energy-storagetechnologies/, accessed 2011.1).

Figure 3. TOUGH-FLAC coupled analysis

Figure 4. Model grid for TOUGH-FLAC simulations of underground CAES in a lined rock cavern.

Figure 5. Calculated (a) pressure and (b) temperature evolution within the cavern (P1), concrete lining (P2) and rock (P3) during 1 daily compression and decompression cycle. (See Figure 4 for exact locations of $\mathrm{P} 1, \mathrm{P} 2$ and $\mathrm{P} 3$ ).

Figure 6. Calculated gas saturation after 1 and 15 years operation at an average cavern pressure of $6.25 \mathrm{MPa}$.

Figure 7. Calculated (a) gas pressure and (b) temperature evolution during a daily compression and decompression cycle.

Figure 8. Calculated radial displacement evolution of the inner surface of the concrete liner during 1 daily compression and decompression cycle. 
Figure 9. Calculated evolution of (a) leakage rate and (b) gas saturation within the cavern (P1), concrete lining (P2), and rock (P3) for a constant cavern pressure of $6.25 \mathrm{MPa}$, for the case of a tight concrete lining (See Figure 4 for the exact locations of P1, P2, and P3).

Figure 10. Calculated evolutions of (a) pressure and (b) temperature within the cavern (P1), concrete lining (P2), and rock (P3) during 10 daily compression cycles. (See Figure 4 for the exact locations of $\mathrm{P} 1, \mathrm{P} 2$, and $\mathrm{P} 3)$.

Figure 11. Calculated evolution of (a) leakage rate and (b) gas saturation within the cavern (P1), concrete lining (P2), and rock (P3) for a constant cavern pressure of 6.25 MPa for the case of a leaky concrete lining (See Figure 4 for the exact locations of P1, P2, and P3).

Figure 12. Calculated evolutions of gas pressure within the cavern (P1), concrete lining (P2), and rock (P3) during 10 daily compression cycles for the case of a leaky concrete lining (See Figure 4 for the exact locations of $\mathrm{P} 1, \mathrm{P} 2$, and $\mathrm{P} 3$ ).

Figure 13. Calculated evolutions of pressure within the cavern (P1), concrete lining (P2), and rock (P3) for the case of shut-in test with a leaky concrete lining (See Figure 4 for the exact locations of $\mathrm{P} 1, \mathrm{P} 2$, and $\mathrm{P} 3)$.

Figure 14. Calculated evolutions of pressure the cavern (P1), concrete lining (P2), and rock (P3) for a leaky system with relatively permeable concrete lining and rock, but with increased air injection to keep the average cavern pressure constant (See Figure 4 for the exact locations of P1, P2, and P3).

Figure 15. Calculated evolution of daily leakage percentage for different combinations of concrete lining and rock permeability.

Figure 16. Calculated daily leakage percentage versus gas saturation in the concrete lining.

Figure 17. Calculated evolution of daily leakage percentage for different values of van Genuchten's parameter $\mathrm{P}_{0}$ in the capillary pressure curve.

Figure 18. Energy balance terms for the tight lining case.

Figure 19. Energy balance terms for the leaky lining case. 
Table 1

\begin{tabular}{|c|c|c|c|}
\hline \multirow{2}{*}{ Property } & \multicolumn{3}{|c|}{ Material } \\
\cline { 2 - 4 } & Rock mass & EDZ & Concrete lining \\
\hline Young's modulus, E (GPa) & 35 & 35 & 35 \\
\hline Poisson's ratio, $v(-)$ & 0.3 & 0.3 & 0.3 \\
\hline Thermal expansion coefficient $\left({ }^{\circ} \mathrm{C}^{-1}\right)$ & $1 \times 10^{-5}$ & $1 \times 10^{-5}$ & $1 \times 10^{-5}$ \\
\hline Effective porosity, $\phi(-)$ & 0.01 & 0.01 & 0.1 \\
\hline Permeability, $k,\left(\mathrm{~m}^{2}\right)$ & $1 \times 10^{-17}$ & $1 \times 10^{-17}$ & $1 \times 10^{-20}$ \\
\hline Residual gas saturation $(-)$ & 0.0 & 0.0 & 0.0 \\
\hline Residual liquid saturation $(-)$ & 0.01 & 0.01 & 0.01 \\
\hline van Genuchten, $P_{0}(\mathrm{MPa})$ & 1.47 & 1.47 & 1.47 \\
\hline van Genuchten $() m,(-)$ & 0.595 & 0.595 & 0.595 \\
\hline Thermal conductivity $\lambda\left(\mathrm{J} / \mathrm{s} / \mathrm{m}{ }^{\circ} \mathrm{K}\right)$ & 3 & 3 & 3 \\
\hline Specific heat $\left(\mathrm{J} / \mathrm{kg}{ }^{\circ} \mathrm{K}\right)$ & 900 & 900 & 900 \\
\hline
\end{tabular}

Table 2

\begin{tabular}{|l|c|c|c|c|}
\hline & \multicolumn{2}{|c|}{ Initial gas saturation (-) } & Leakage rate $(\mathrm{kg} / \mathrm{s})$ & Daily leakage \\
& Concrete lining & Rock & & percent (\%) \\
\hline Analysis & 0.74 & 0.69 & $1.04 \times 10^{-3}(89.9 \mathrm{~kg} /$ day $)$ & 12 \\
\cline { 2 - 5 } conditions & 0.29 & 0.2 & $6.38 \times 10^{-5}(5.51 \mathrm{~kg} /$ day $)$ & 0.8 \\
\hline
\end{tabular}

Table 3.

\begin{tabular}{|c|c|c|c|c|c|}
\hline \multicolumn{2}{|c|}{ Cavern depth } & \multicolumn{2}{c|}{$100 \mathrm{~m}$ depth } & \multicolumn{2}{c|}{$500 \mathrm{~m}$ depth } \\
\hline \multicolumn{2}{|c|}{ Permeability conditions } & Tight & Leaky & Tight & Leaky \\
\hline Gas saturation & Concrete lining & 0.6 & 0.74 & 0.2 & 0.25 \\
\cline { 2 - 6 }$(-)$ & Rock & 0.9 & 0.69 & 0.05 & 0.2 \\
\hline \multicolumn{2}{|c|}{ Leakage rate (kg/day) } & $8.6 \times 10^{-2}$ & $8.99 \times 10^{1}$ & $1.3 \times 10^{-3}$ & $8.64 \times 10^{-1}$ \\
\hline \multicolumn{2}{|c|}{ Daily leakage percentage (\%) } & 0.012 & 12 & 0.0002 & 0.12 \\
\hline
\end{tabular}


Table 4.

\begin{tabular}{|c|c|c|c|}
\hline Phases & Cases & Tight lining $(*)$ & Leaky lining \\
\hline \multirow{7}{*}{ Compression } & Total injected energy, $E_{m_{i}}$ (Joule) & $1.8420 \mathrm{E}+8$ & $1.8428 \mathrm{E}+8$ \\
\hline & Total energy change in the cavern, $E_{s}$ (Joule) & $1.3260 \mathrm{E}+8$ & $1.1840 \mathrm{E}+8$ \\
\hline & Energy loss by air leakage, $E_{l}$ (Joule) & $3.8257 \mathrm{E}+5$ & $1.7956 \mathrm{E}+7$ \\
\hline & Energy loss by heat advection, $Q_{a}$ (Joule) & $2.2070 \mathrm{E}+4$ & $5.9314 \mathrm{E}+6$ \\
\hline & Energy loss by heat conduction, $Q_{c}$ (Joule) & $5.1510 \mathrm{E}+7$ & $4.1991 \mathrm{E}+7$ \\
\hline & Total energy loss, $E_{l}+Q_{a}+Q_{a}($ Joule $)$ & $5.1915 \mathrm{E}+7$ & $6.5879 \mathrm{E}+7$ \\
\hline & $\begin{array}{l}\text { Total energy loss against } \\
\text { total injected energy, }\left(E_{l}+Q_{a}+Q_{a}\right) / E_{m_{i}}(-)\end{array}$ & 0.28 & 0.36 \\
\hline \multirow{7}{*}{ Decompression } & Total produced energy, $E_{m_{p}}$ (Joule) & $-1.7695 \mathrm{E}+8$ & $-1.7617 \mathrm{E}+8$ \\
\hline & Total energy change in the cavern, $E_{s}$ (Joule) & $-1.3288 \mathrm{E}+8$ & $-1.2862 \mathrm{E}+8$ \\
\hline & Energy loss by air leakage, $E_{l}($ Joule) & $-3.7087 \mathrm{E}+4$ & $-3.6282 \mathrm{E}+6$ \\
\hline & Energy loss by heat advection, $Q_{a}$ (Joule) & $-1.2133 \mathrm{E}+4$ & $-1.1554 \mathrm{E}+6$ \\
\hline & Energy loss by heat conduction, $Q_{c}$ (Joule) & $-4.4015 \mathrm{E}+7$ & $-4.2772 \mathrm{E}+7$ \\
\hline & Total energy loss, $E_{l}+Q_{a}+Q_{a}($ Joule $)$ & $-4.4065 \mathrm{E}+7$ & $-4.7555 \mathrm{E}+7$ \\
\hline & $\begin{array}{l}\text { Total energy loss against } \\
\text { total injected energy, }\left(E_{l}+Q_{a}+Q_{a}\right) / E_{m_{i}}(-)\end{array}$ & -0.24 & -0.26 \\
\hline \multicolumn{2}{|r|}{ Min. temperature during the cycle $\left({ }^{\circ} \mathrm{C}\right)$} & 4.9 & 5.6 \\
\hline \multicolumn{2}{|c|}{ Max. temperature during the cycle $\left({ }^{\circ} \mathrm{C}\right)$} & 19.4 & 20.2 \\
\hline
\end{tabular}

(* base case simulation) 
Table 5.

\begin{tabular}{|c|c|c|c|c|c|}
\hline \multirow[t]{2}{*}{ Phase } & \multirow[t]{2}{*}{ Cases } & \multicolumn{3}{|c|}{$\begin{array}{c}\text { Injection Temperature } \\
\left({ }^{\circ} \mathrm{C}\right)\end{array}$} & \multirow{2}{*}{$\begin{array}{l}\text { Thermal conductivity } \\
\qquad\left(\mathrm{J} / \mathrm{s} \mathrm{m}^{\circ} \mathrm{K}\right) \\
30\end{array}$} \\
\hline & & 13 & 31 & 46 & \\
\hline \multirow[t]{4}{*}{$\begin{array}{l}\text { Compres } \\
\text { sion }\end{array}$} & $\begin{array}{l}\text { Total injected energy, } \\
E_{m_{i}}(\text { Joule })\end{array}$ & $1.7918 \mathrm{E}+8$ & $1.9046 \mathrm{E}+8$ & $1.9985 \mathrm{E}+8$ & $1.8419 \mathrm{E}+8$ \\
\hline & $\begin{array}{l}\text { Energy loss by heat } \\
\text { conduction, } Q_{c} \text { (Joule) }\end{array}$ & $4.6761 \mathrm{E}+7$ & $5.7047 \mathrm{E}+7$ & $6.5419 \mathrm{E}+7$ & $5.4572 \mathrm{E}+7$ \\
\hline & $\begin{array}{l}\text { Total energy loss, } \\
E_{l}+Q_{a}+Q_{a}(\text { Joule })\end{array}$ & $4.6850 \mathrm{E}+7$ & $5.7137 \mathrm{E}+7$ & $6.5510 \mathrm{E}+7$ & $5.4658 \mathrm{E}+7$ \\
\hline & $\begin{array}{l}\text { Total energy loss } \\
\text { against } \\
\text { total injected energy, } \\
\left(E_{l}+Q_{a}+Q_{a}\right) / E_{m_{i}}(-)\end{array}$ & 0.26 & 0.30 & 0.33 & 0.30 \\
\hline \multirow[t]{4}{*}{$\begin{array}{l}\text { Decompr } \\
\text { ession }\end{array}$} & $\begin{array}{l}\text { Total produced energy, } \\
E_{m_{p}} \text { (Joule) }\end{array}$ & $-1.7648 \mathrm{E}+8$ & $-1.7744 \mathrm{E}+8$ & $-1.7823 \mathrm{E}+8$ & $-1.7839 \mathrm{E}+8$ \\
\hline & $\begin{array}{l}\text { Energy loss by heat } \\
\text { conduction, } Q_{c} \text { (Joule) }\end{array}$ & $-4.4096 \mathrm{E}+7$ & $-4.3801 \mathrm{E}+7$ & $-4.3648 \mathrm{E}+7$ & $-4.8507 \mathrm{E}+7$ \\
\hline & $\begin{array}{l}\text { Total energy loss, } \\
E_{l}+Q_{a}+Q_{a} \text { (Joule) }\end{array}$ & $-4.4145 \mathrm{E}+7$ & $-4.3850 \mathrm{E}+7$ & $-4.3681 \mathrm{E}+7$ & $-4.8554 \mathrm{E}+7$ \\
\hline & $\begin{array}{l}\text { Total energy loss } \\
\text { against } \\
\text { total injected energy, } \\
\left(E_{l}+Q_{a}+Q_{a}\right) / E_{m_{i}}(-)\end{array}$ & -0.25 & -0.23 & -0.22 & -0.26 \\
\hline \multicolumn{2}{|c|}{$\begin{array}{l}\text { Min. temperature during the cycle } \\
\qquad\left({ }^{\circ} \mathrm{C}\right)\end{array}$} & 4.9 & 6.5 & 7.8 & 10.2 \\
\hline \multicolumn{2}{|c|}{$\begin{array}{l}\text { Max. temperature during the cycle } \\
\qquad\left({ }^{\circ} \mathrm{C}\right)\end{array}$} & 19.1 & 21.6 & 23.6 & 16.0 \\
\hline
\end{tabular}




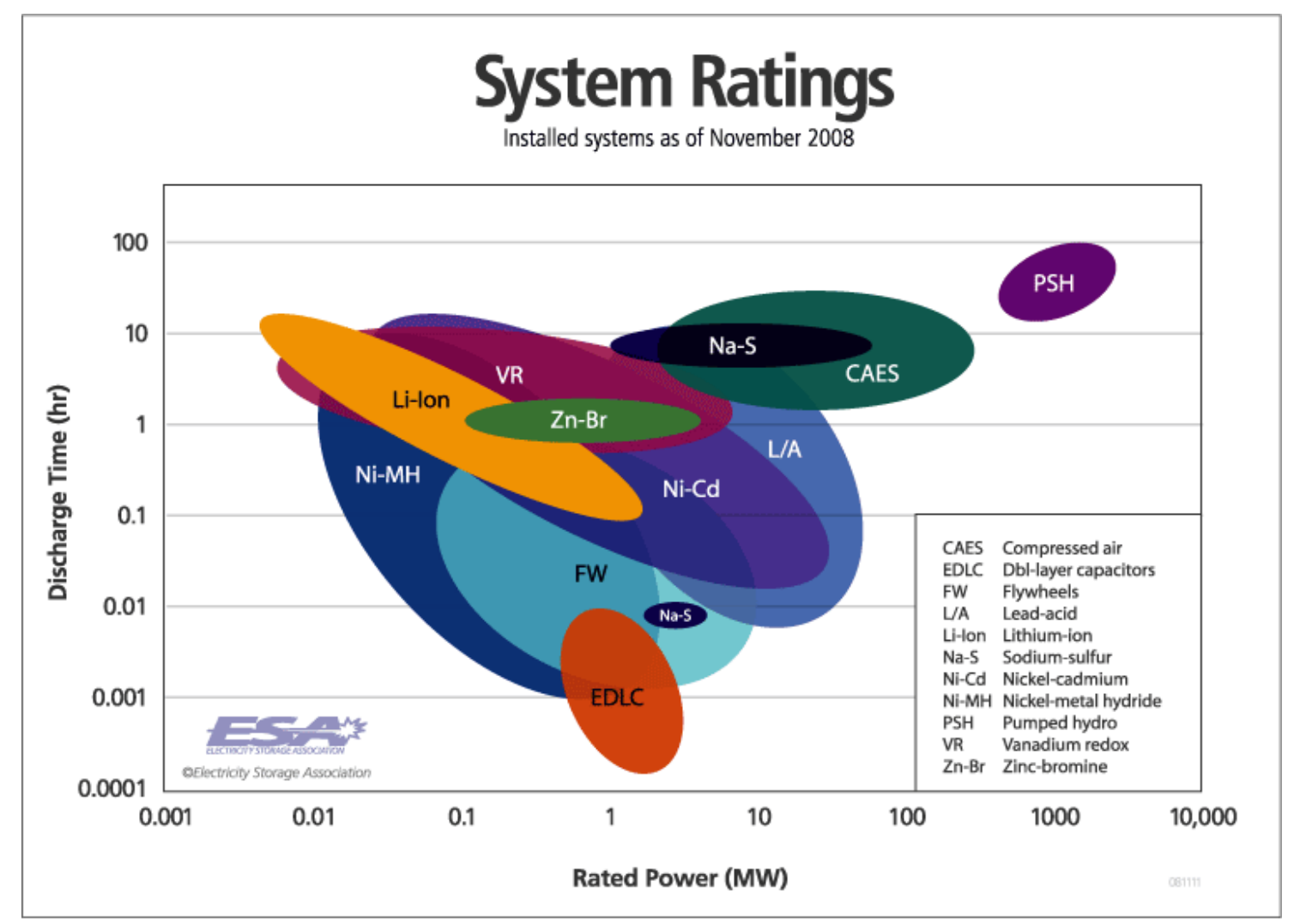

Figure 1.

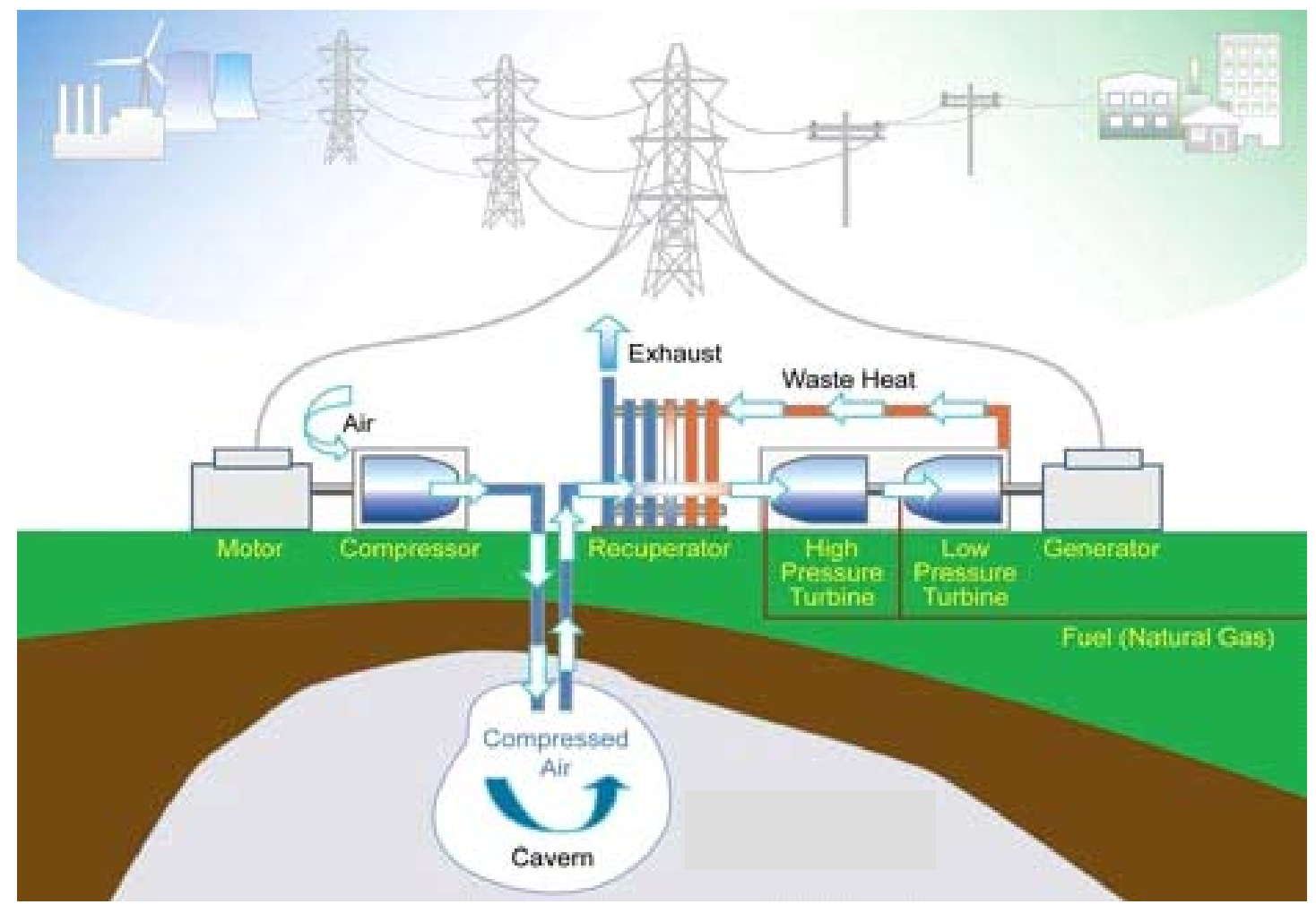

Figure 2. 


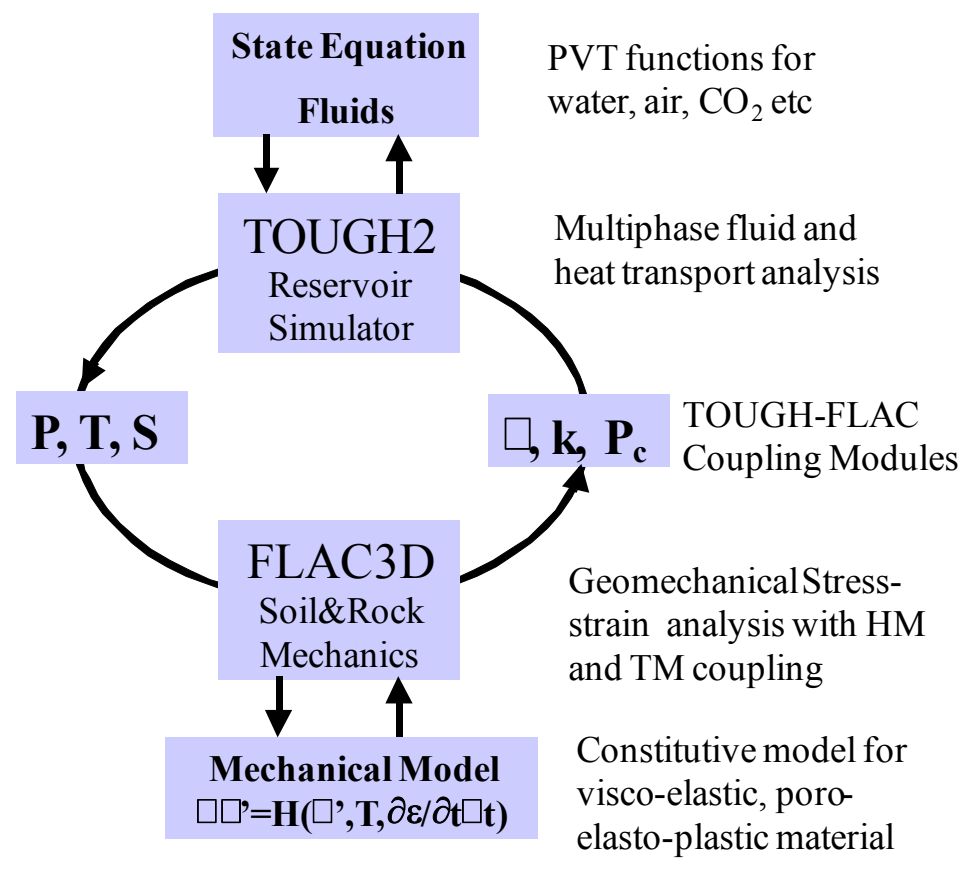

Figure 3.
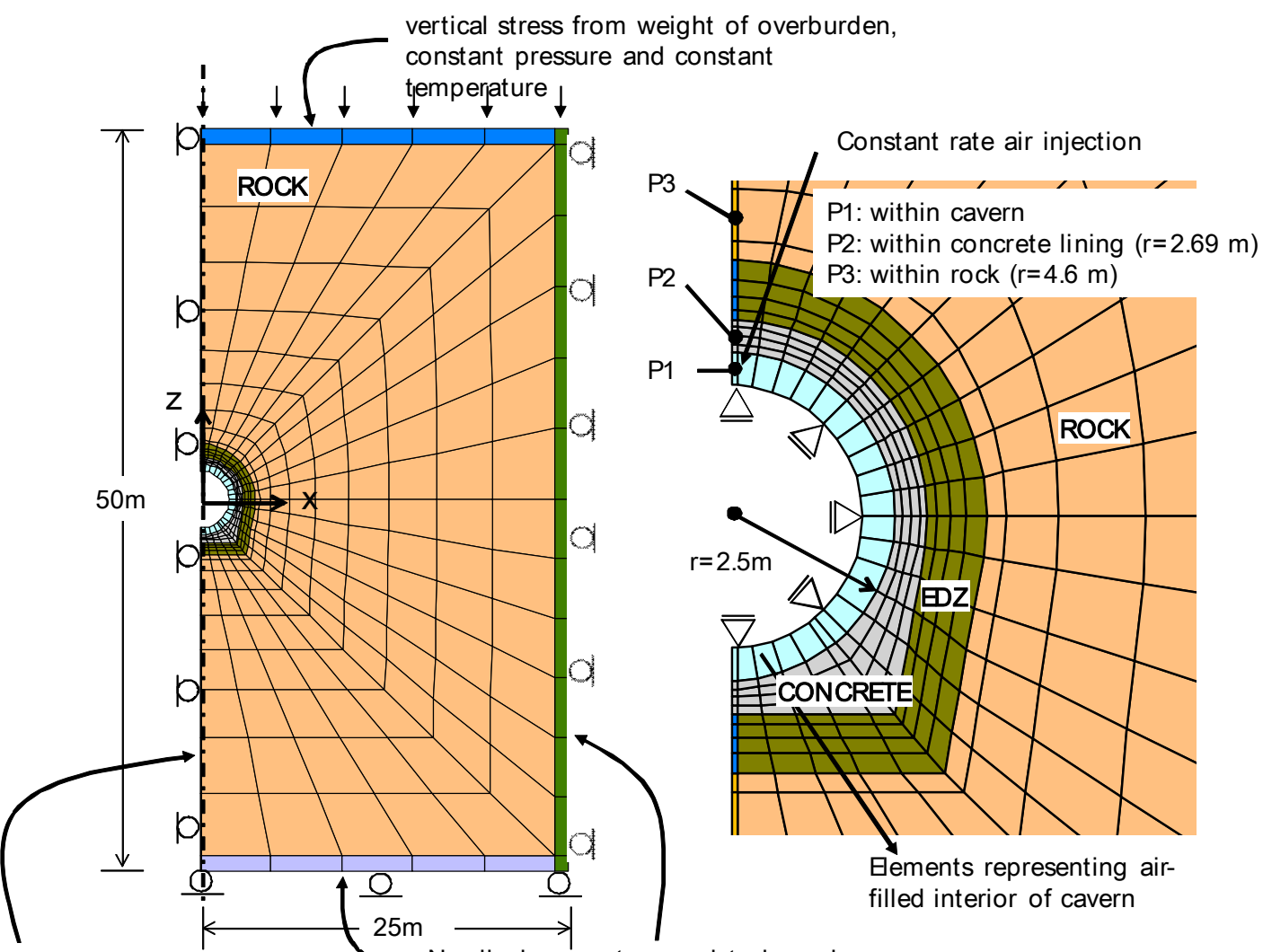

Symmetric boundary with no displacent No displacement normal to boundary, normal to boundary,

constant pressure and constant constant pressure and constant temperature

temperature

Figure 4. 

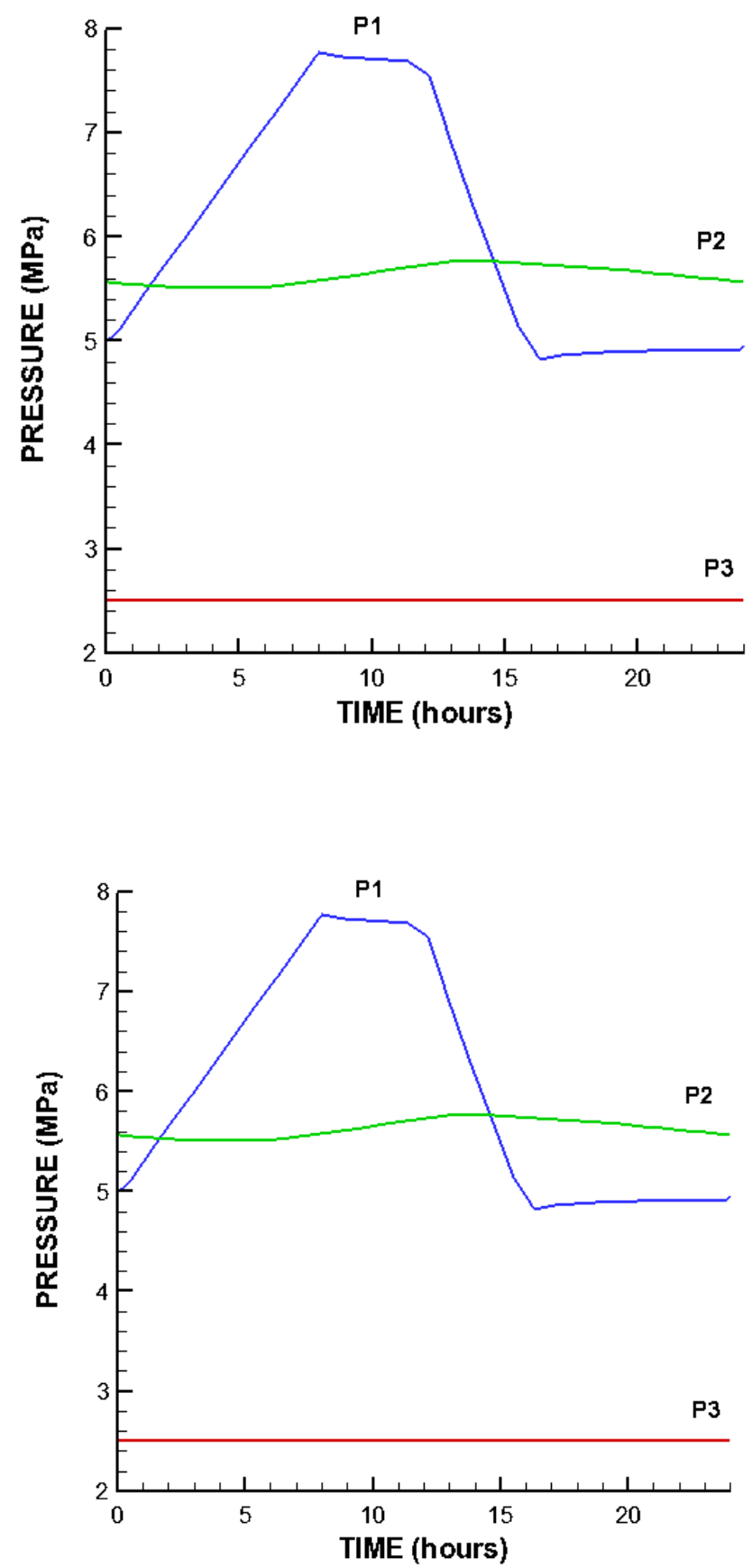

(a) 


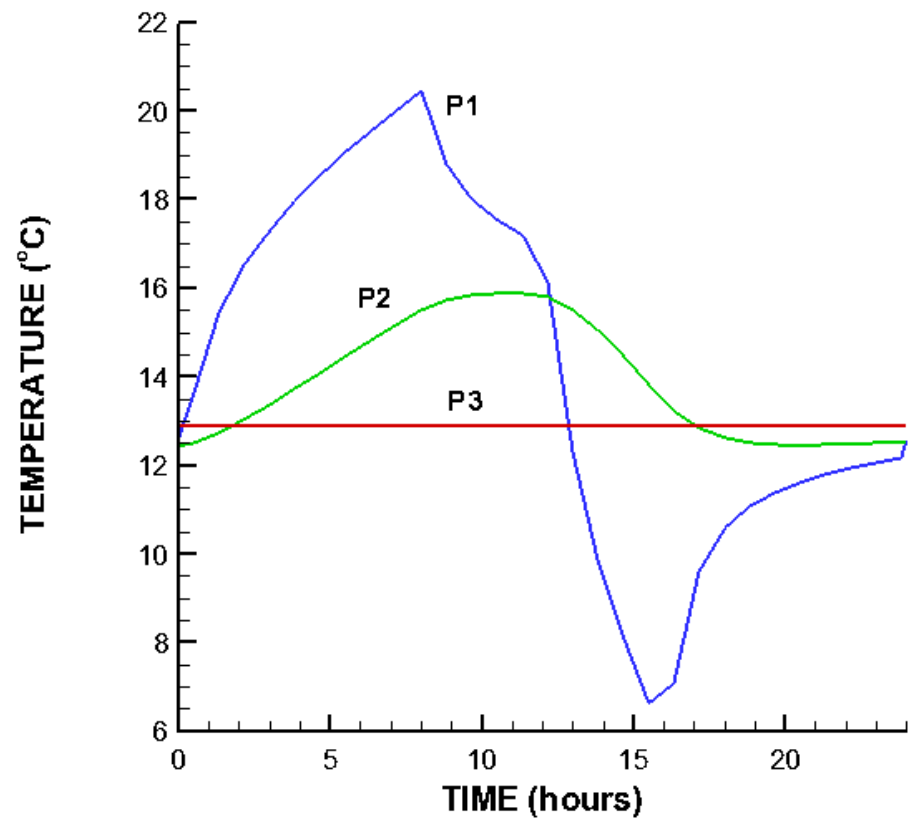

(b)

Figure 5. 


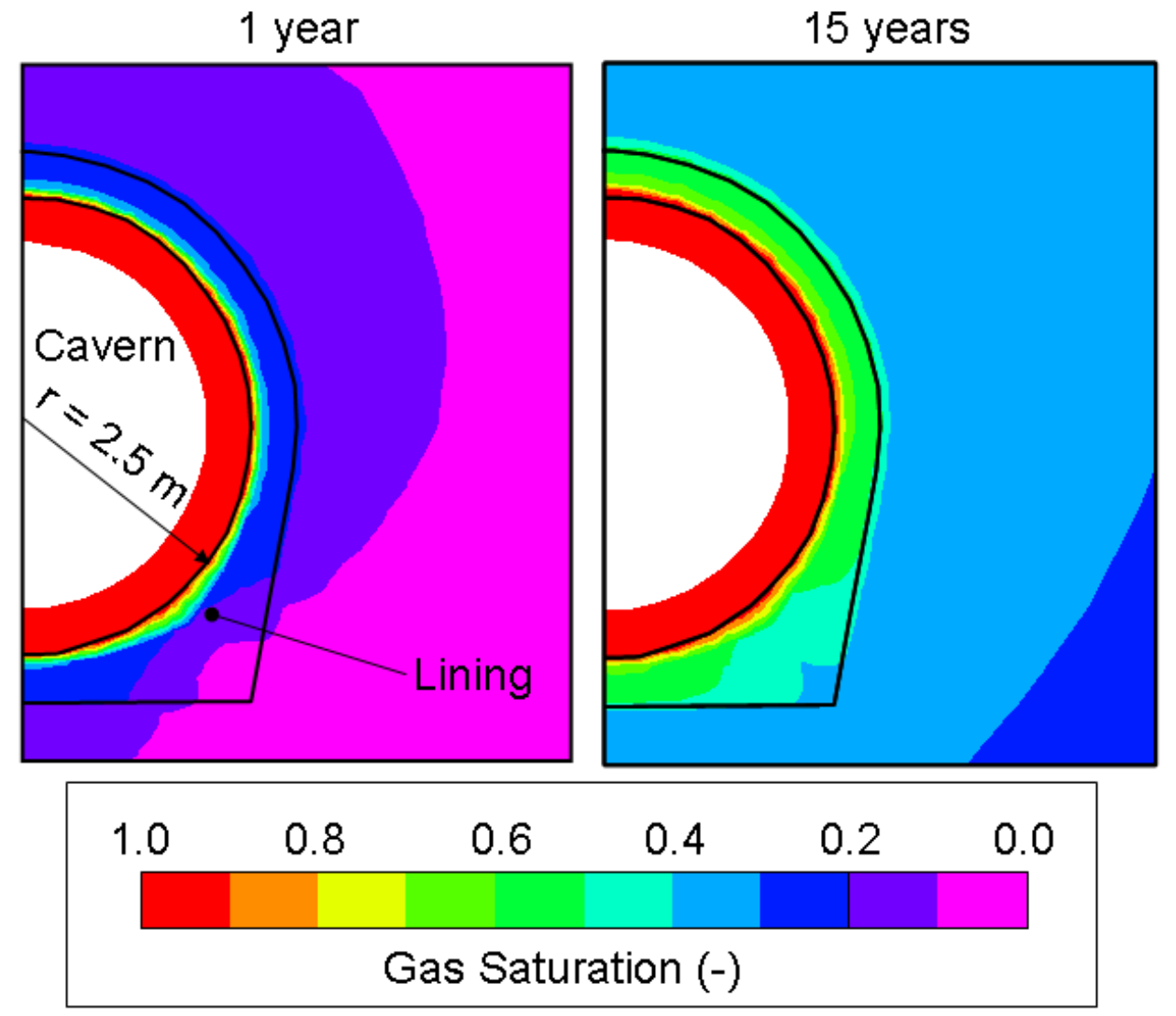

Figure 6. 


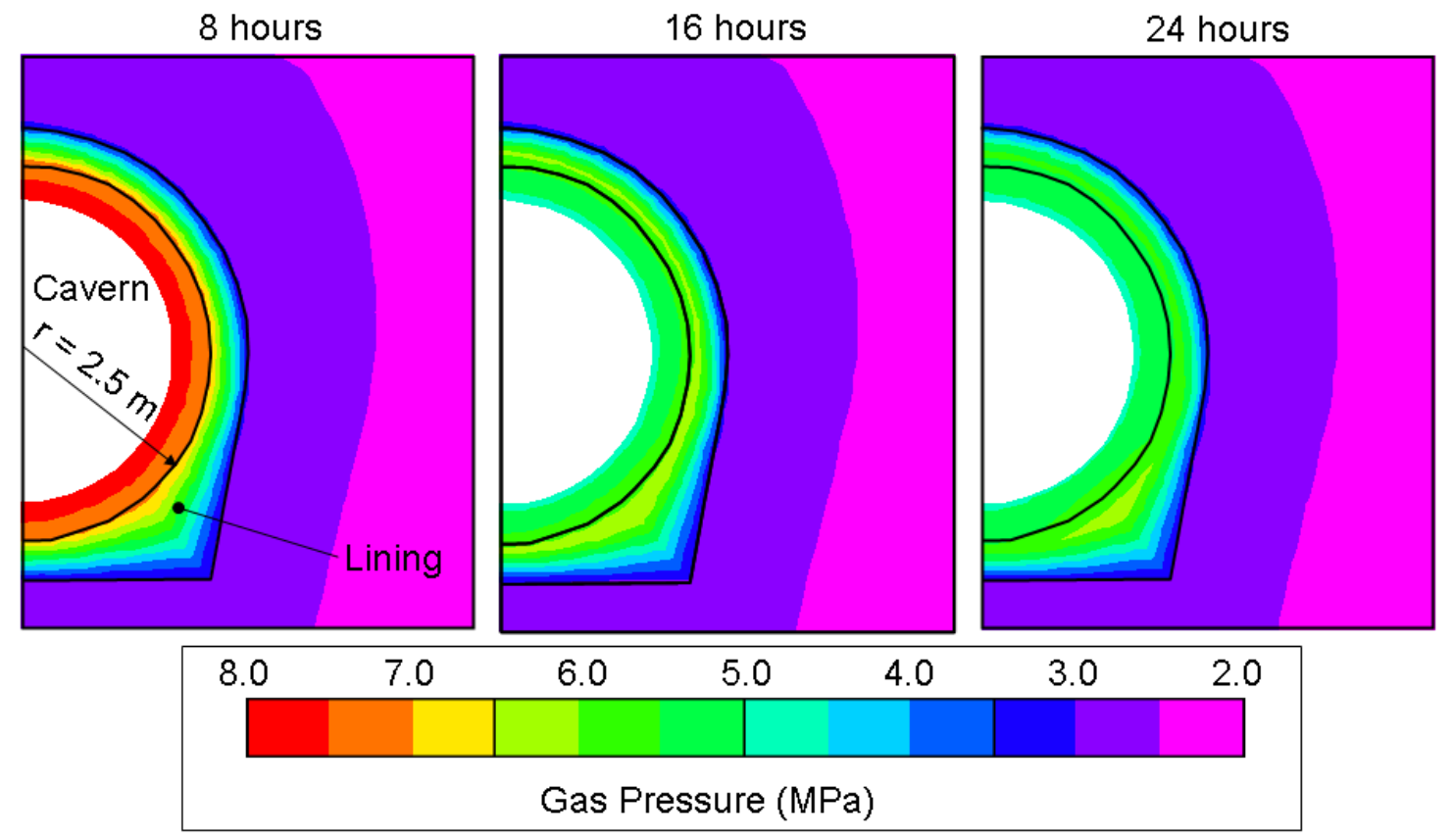

(a)

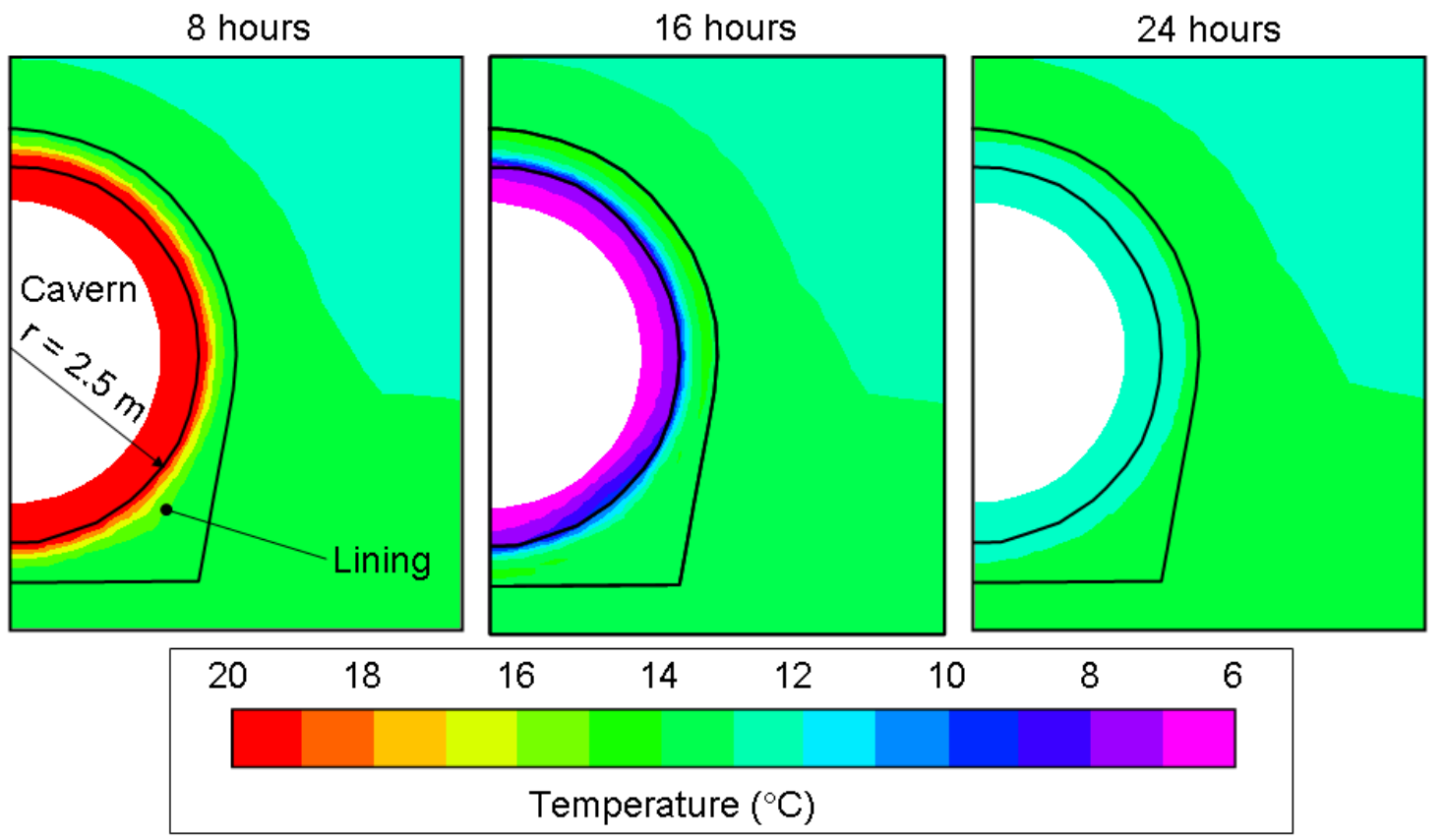

(b)

Figure 7. 


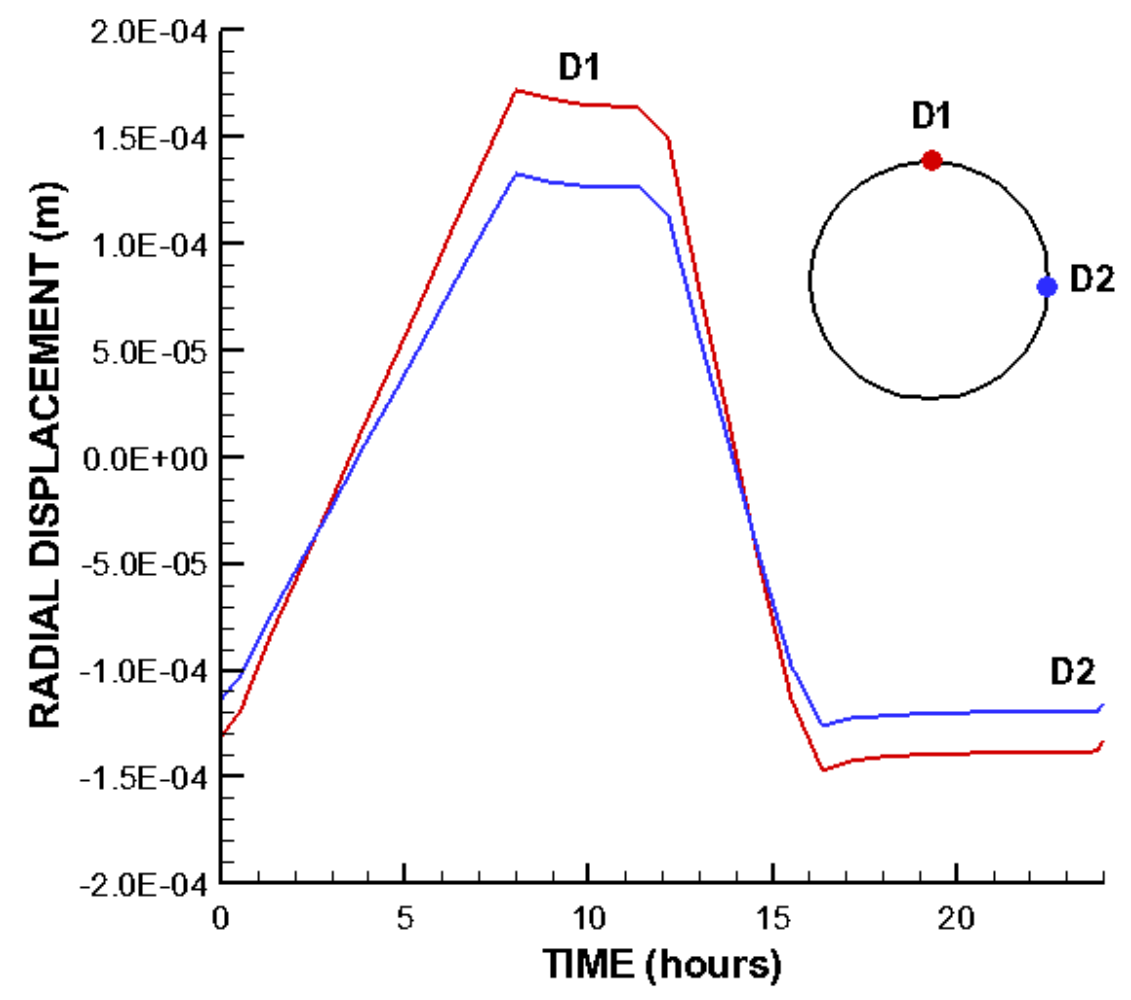

Figure 8. 


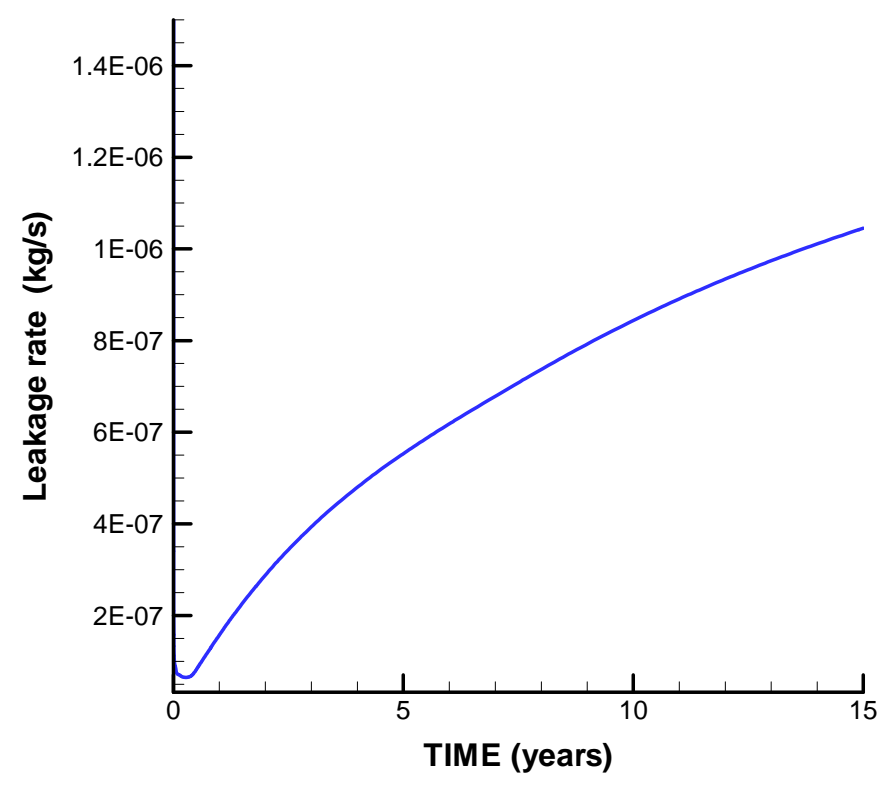

(a)

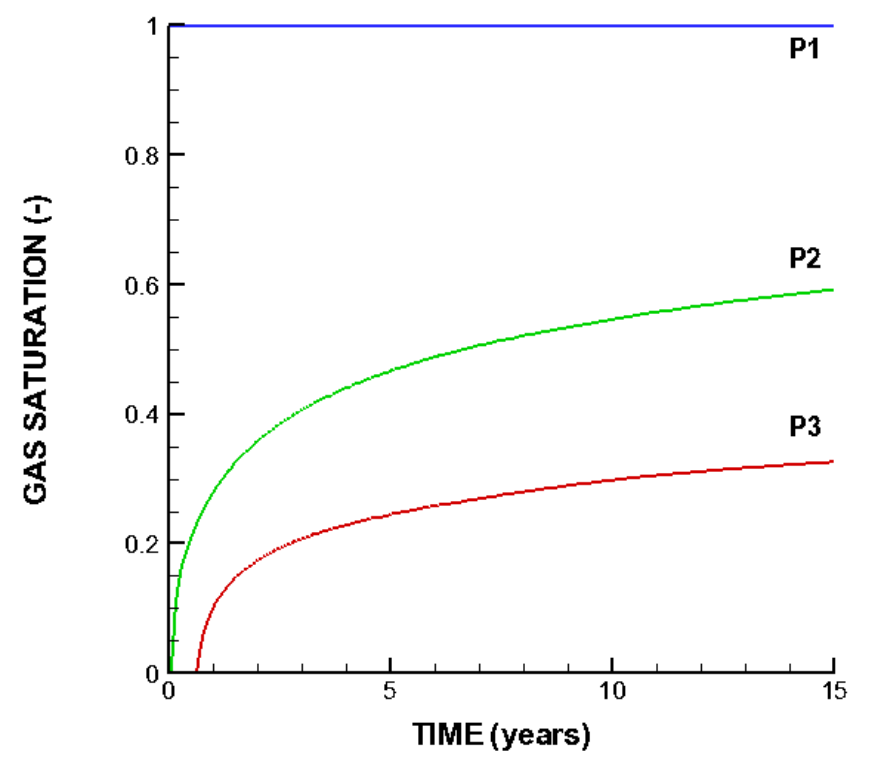

(b)

Figure 9. 


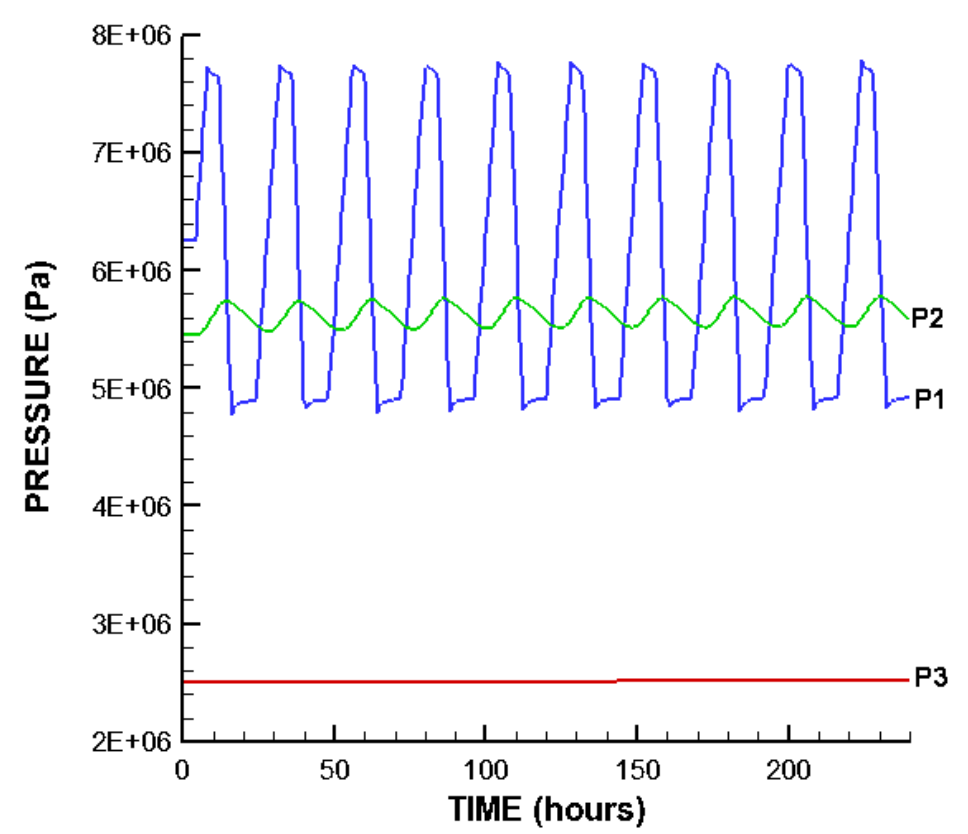

(a)

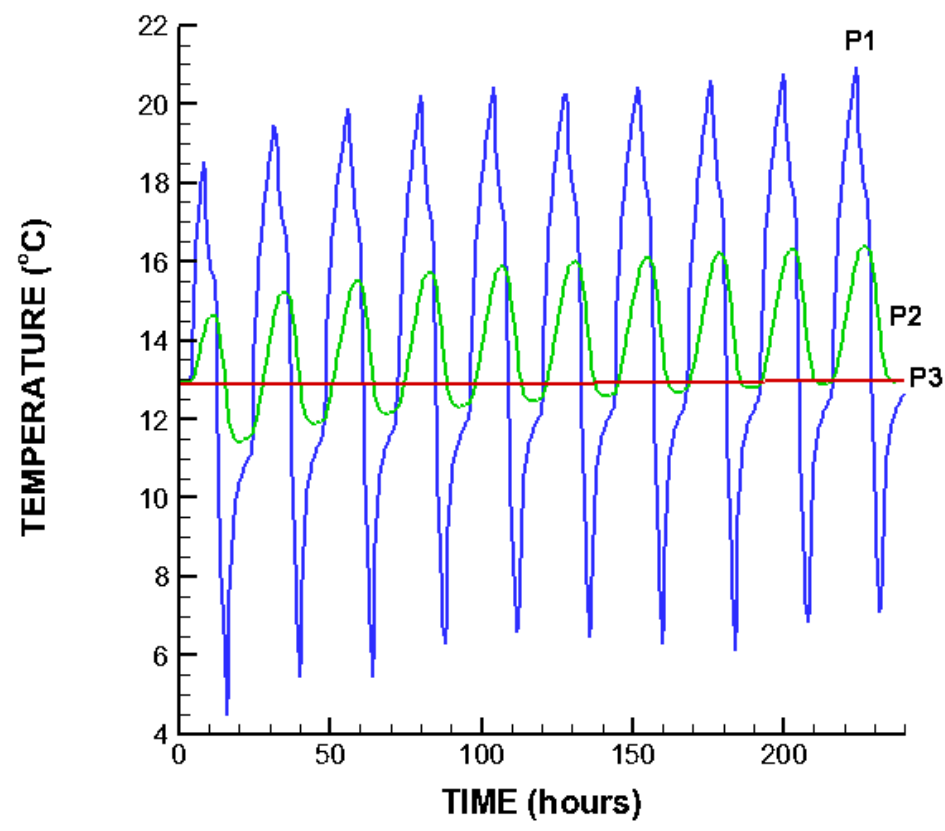

(b)

Figure 10. 


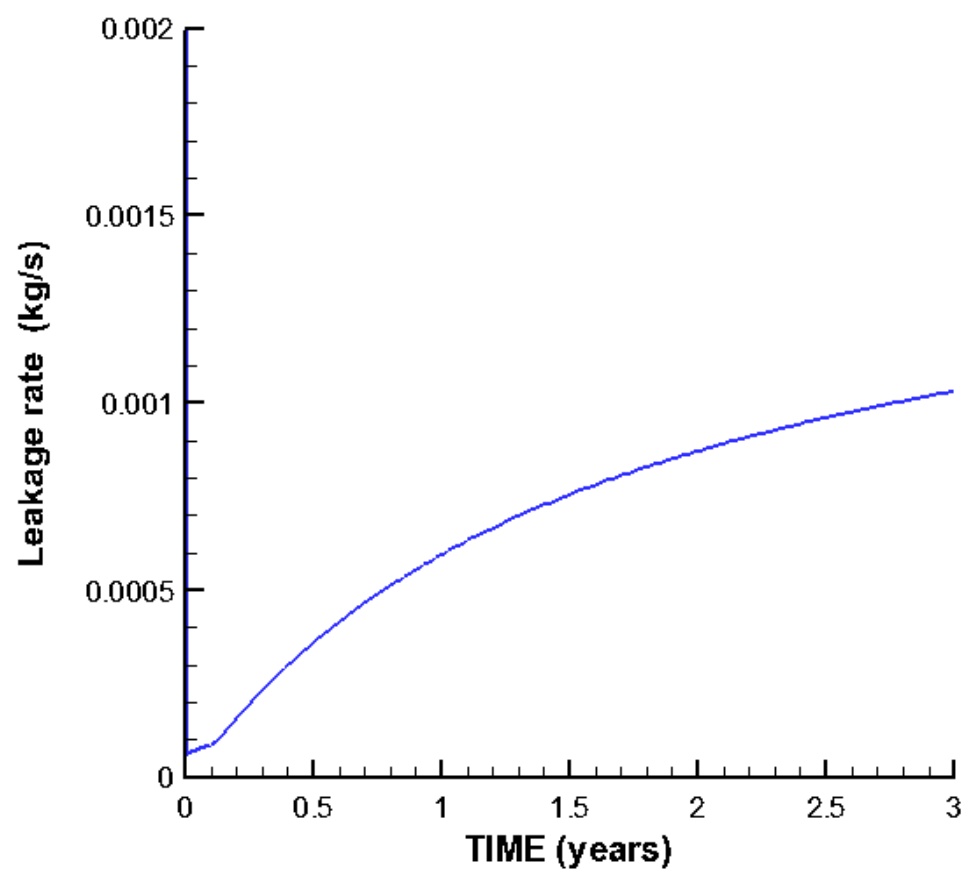

(a)

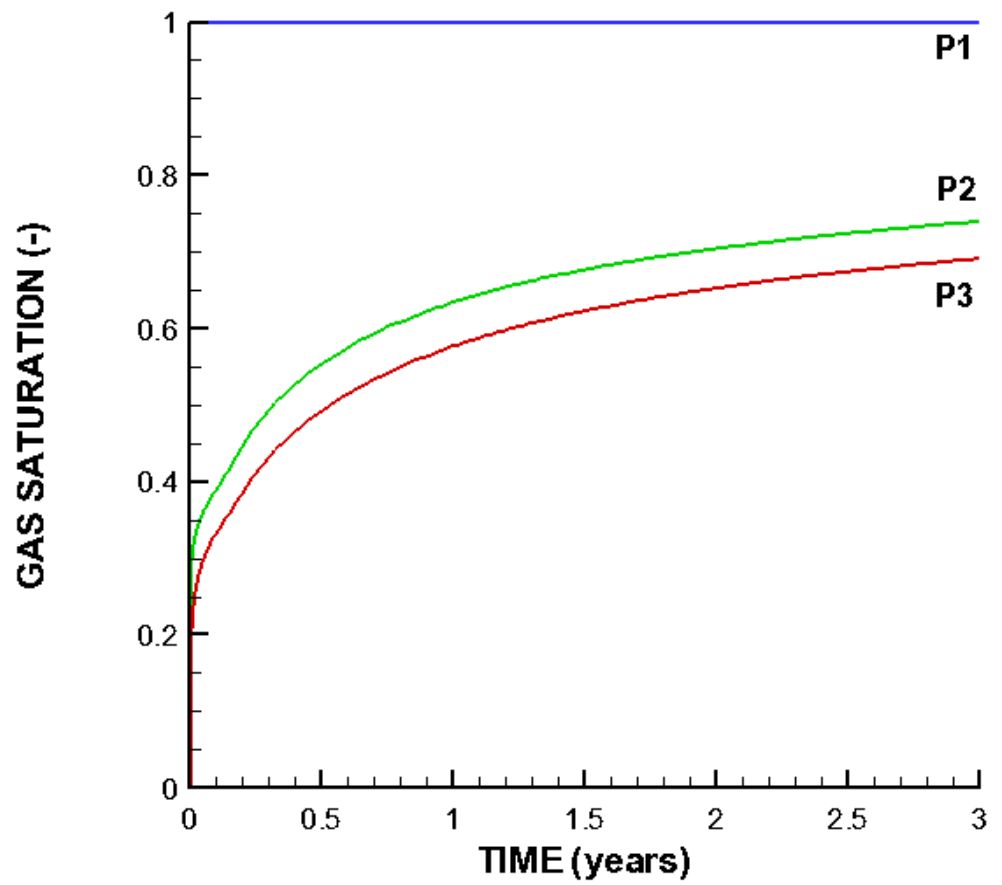

(b)

Figure 11. 


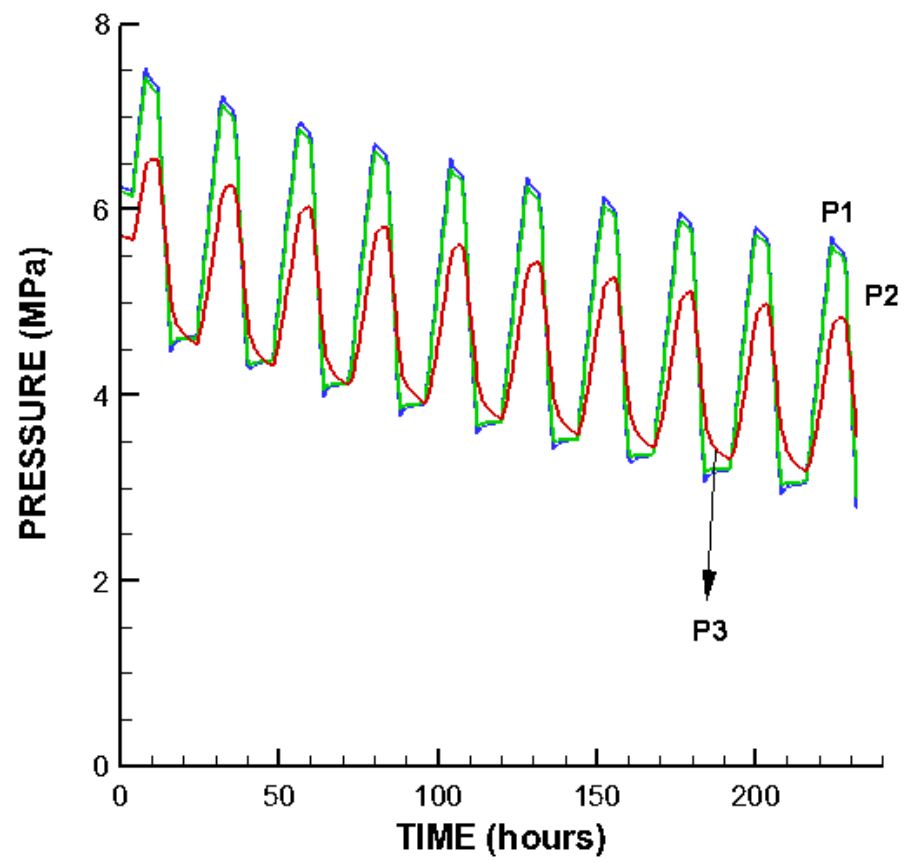

Figure 12.

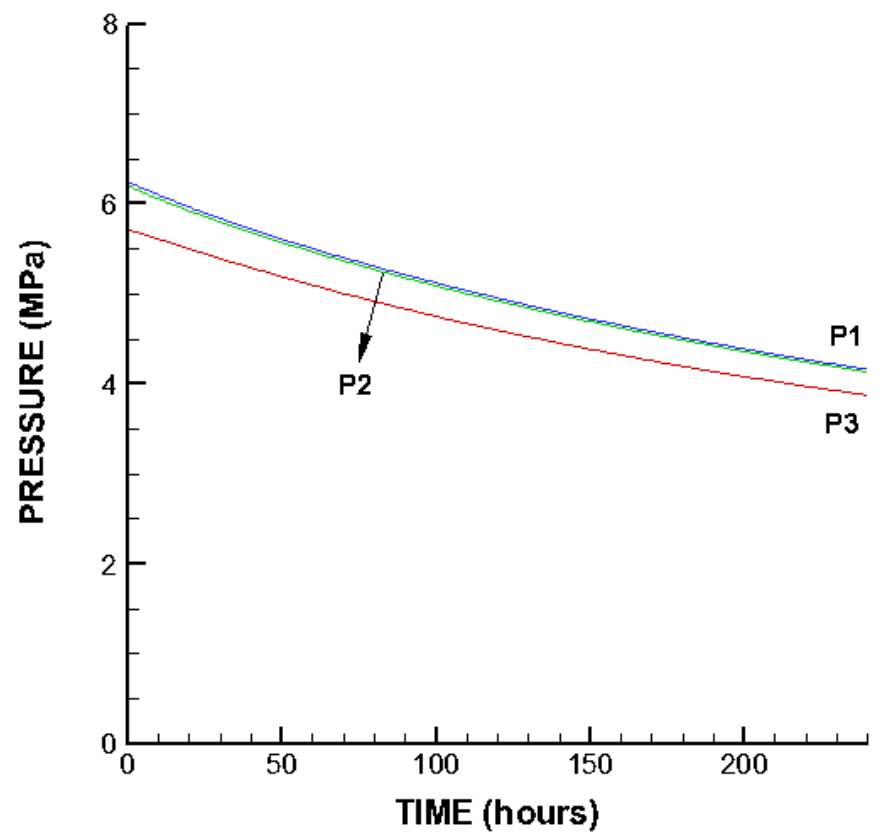

Figure 13. 


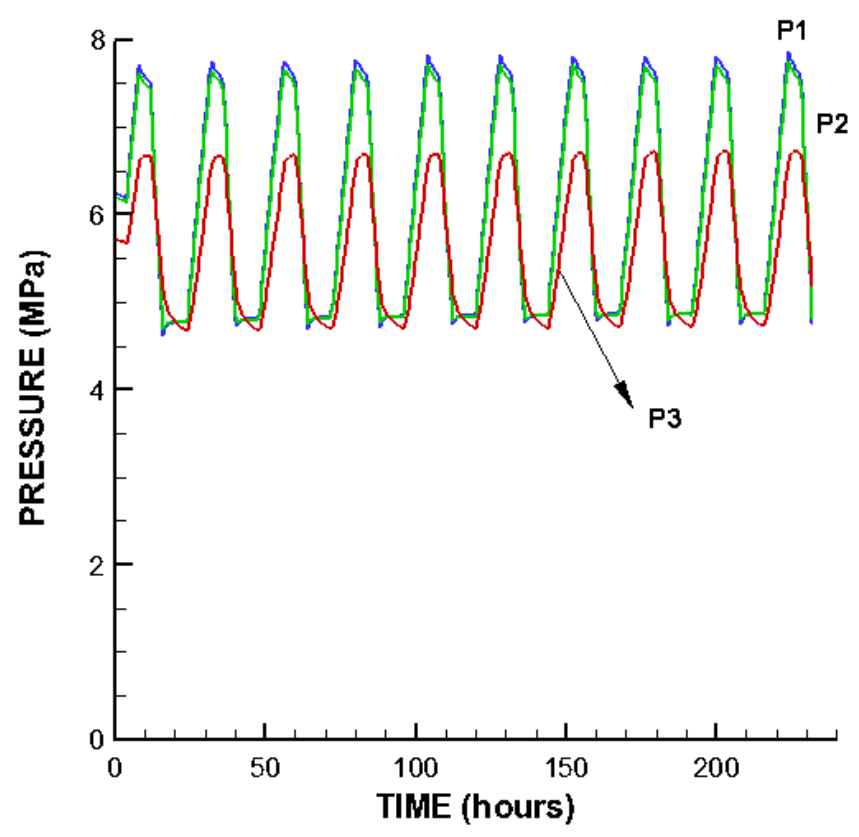

Figure 14.

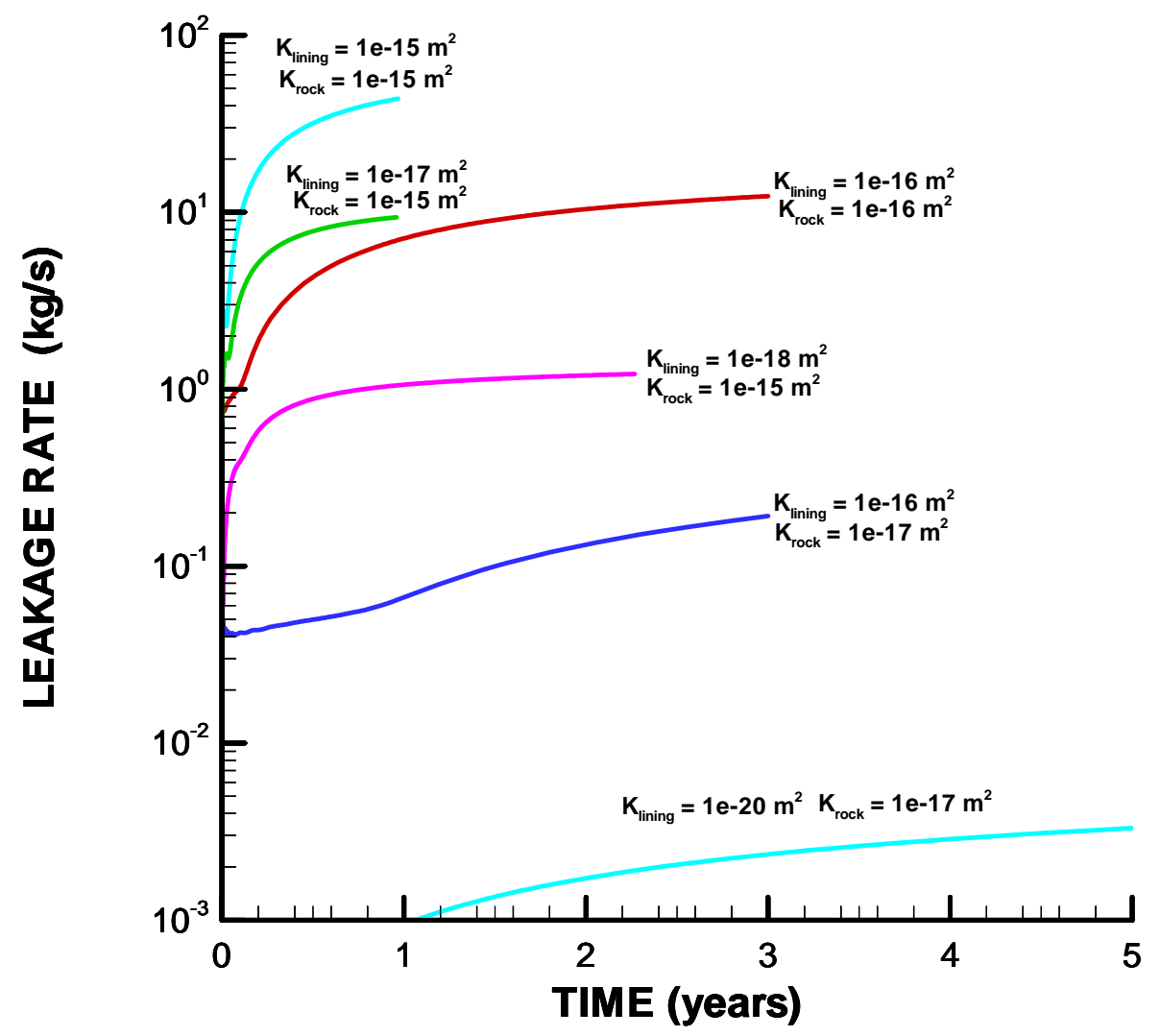

Figure 15. 


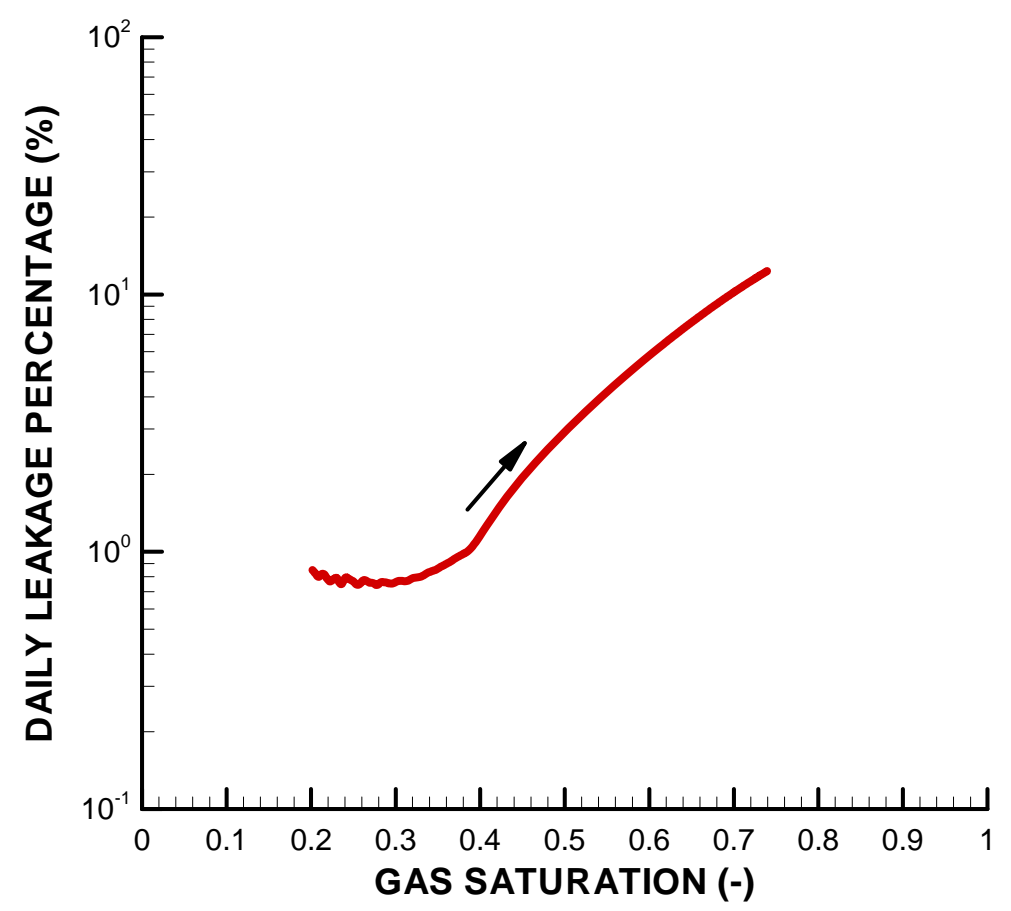

Figure 16.

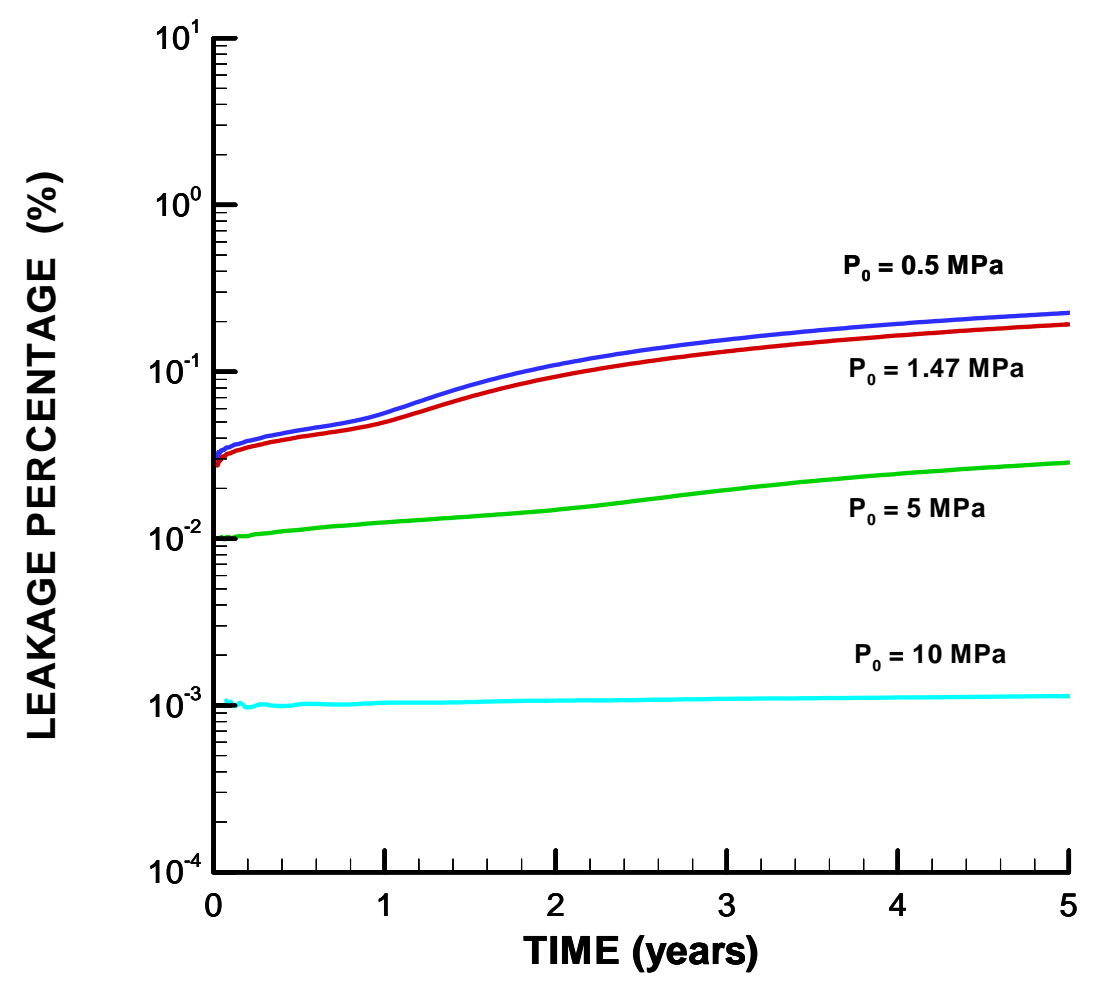

Figure 17. 


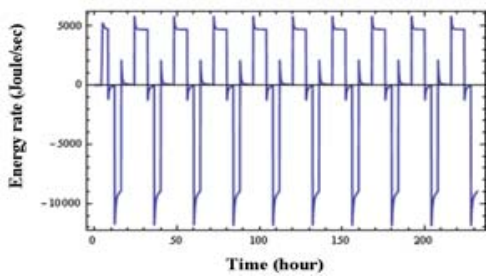

(a) rate of energy change in the storage cavern, $\Delta E_{s}+\Delta W_{s}$

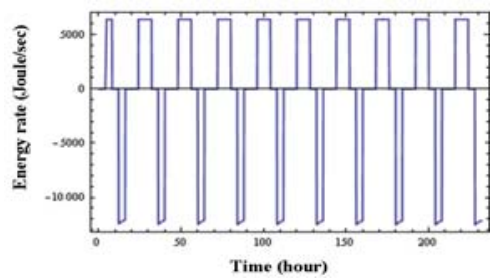

(b) rate of energy due to air injection and production, $\Delta E_{m}+\Delta W_{m}$

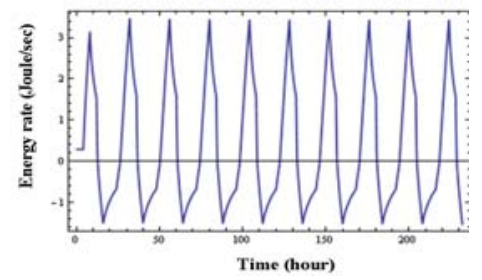

(c) energy loss rate due to air leakage, $\Delta E_{l}+\Delta W_{l}$

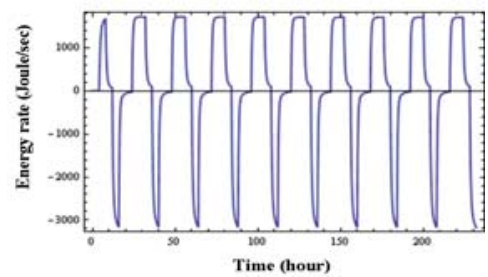

(d) energy loss rate due to heat transfer,

$\Delta Q_{c}+\Delta Q_{a}$

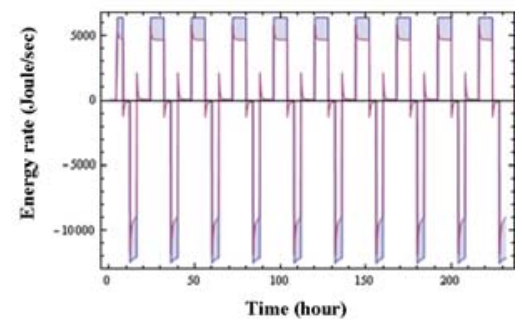

(e) total energy loss, (b)-(a)

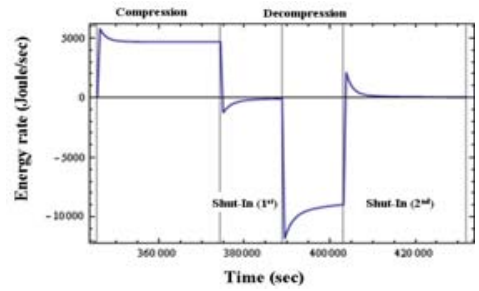

(f) rate of energy change in the storage cavern ( $5^{\text {th }}$ cycle), $\Delta E_{s}+\Delta W_{s}$

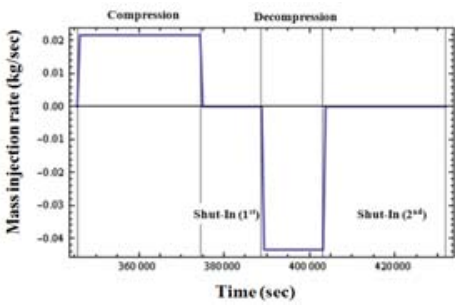

(g) rate of mass flow due to injection and production ( $5^{\text {th }}$ cycle), $m_{m}$

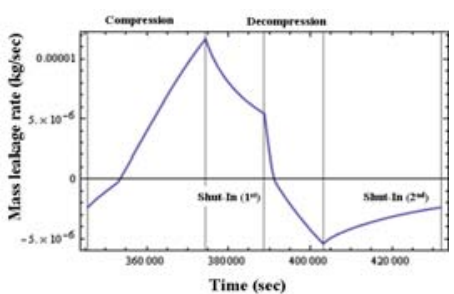

(h) rate of mass flow due to air leakage ( $5^{\text {th }}$ cycle $), m_{l}$

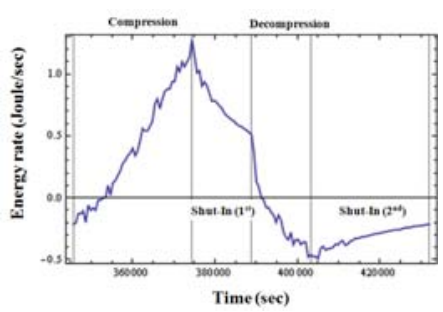

(i) energy loss rate due to heat advection ( $5^{\text {th }}$ cycle), $\Delta Q_{a}$

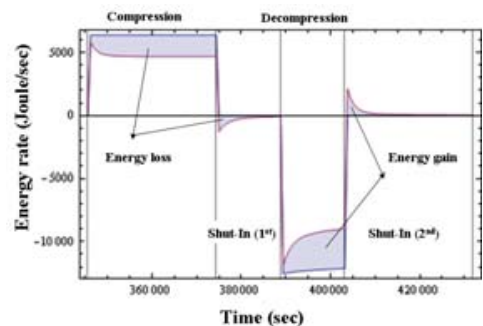

(j) total energy loss ( $5^{\mathrm{m}}$ cycle), (g)-(f)

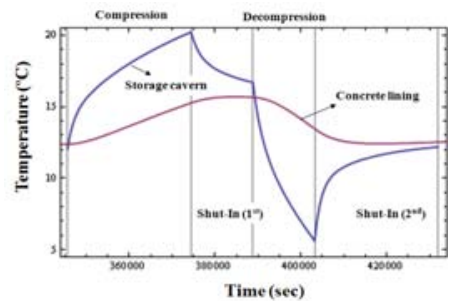

(k) temperature evolution in the cavern and concrete lining ( $5^{\text {th }}$ cycle), $T_{s}$

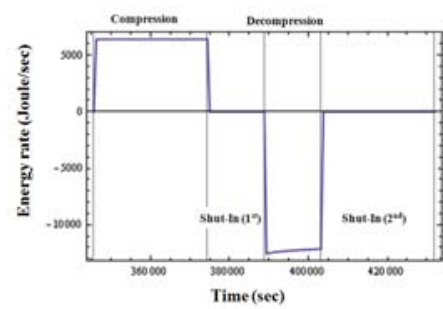

(1) rate of energy due to air injection and production $\left(5^{\text {th }}\right.$ cycle),

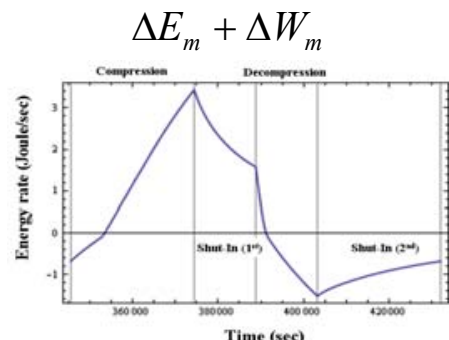

(m) energy loss rate due to air leakage,

$$
\Delta E_{l}+\Delta W_{l}
$$

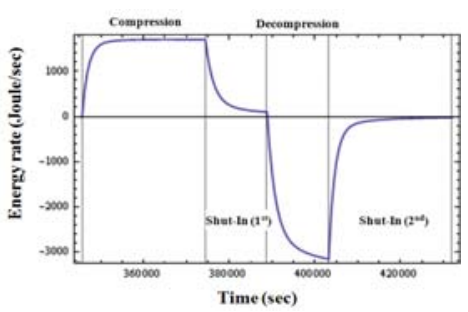

(n) energy loss rate due to heat conduction ( $5^{\text {th }}$ cycle), $\Delta Q_{c}$

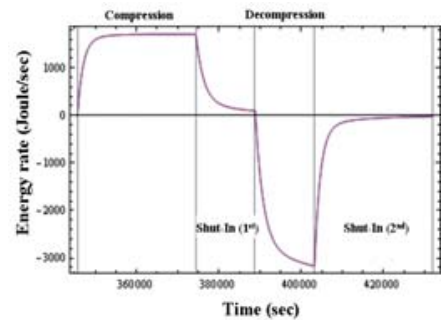

(o) total energy loss ( $5^{\text {th }}$ cycle $),(n)+(i)$

Figure 18. Energy balance terms in the tight lining case. 


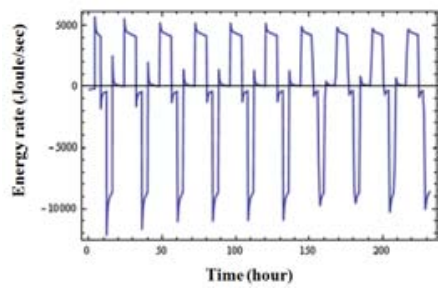

(a) rate of energy change in the storage cavern, $\Delta E_{s}+\Delta W_{s}$

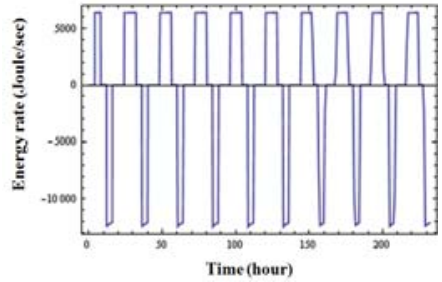

(b) rate of energy due to air injection and production, $\Delta E_{m}+\Delta W_{m}$

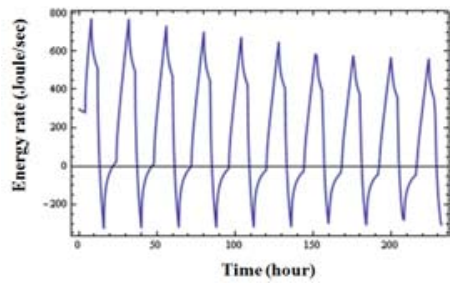

(c) energy loss rate due to air leakage, $\Delta E_{l}+\Delta W_{l}$

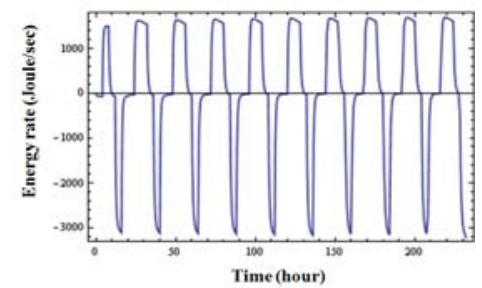

(d) energy loss rate due to heat transfer,

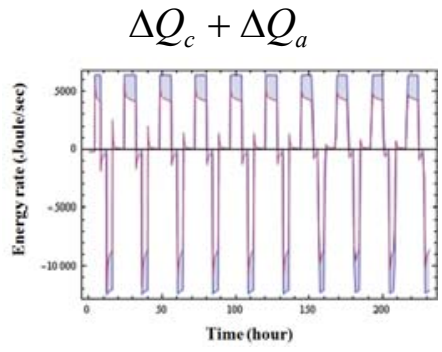

(e) total energy loss, (b)-(a)

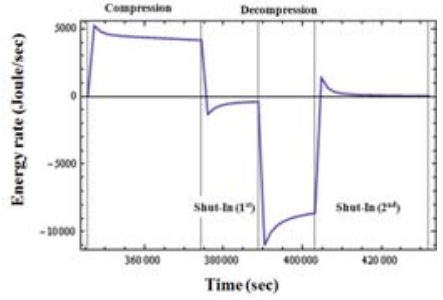

(f) rate of energy change in the storage cavern ( $5^{\text {th }}$ cycle), $\Delta E_{s}+\Delta W_{s}$

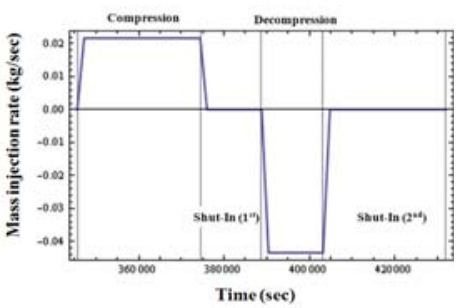

(g) rate of mass flow due to injection and production ( $5^{\text {th }}$ cycle), $m_{m}$

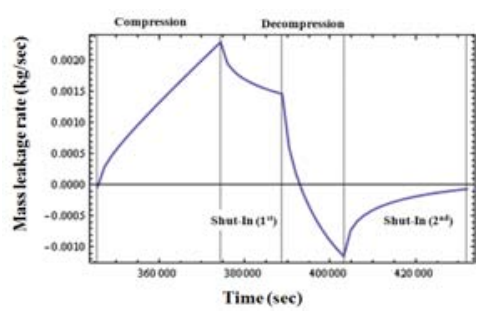

(h) rate of mass flow due to air leakage ( $5^{\text {th }}$ cycle $), m_{l}$

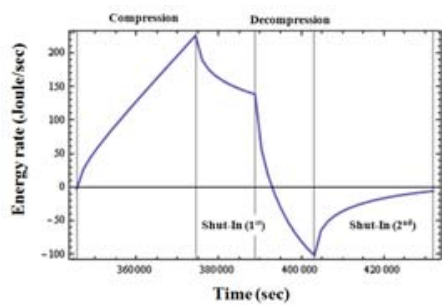

(i) energy loss rate due to heat advection ( $5^{\text {th }}$ cycle), $\Delta Q_{a}$

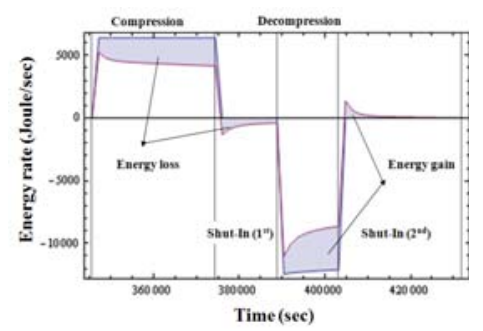

(j) total energy loss ( $5^{\text {th }}$ cycle), (g)-(f)

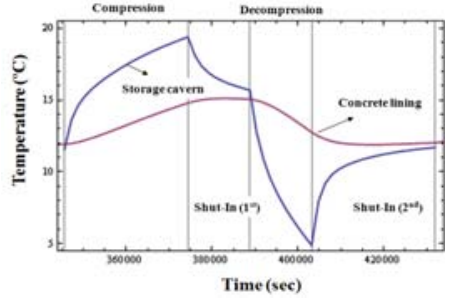

(k) temperature evolution in the cavern and concrete lining ( $5^{\text {th }}$ cycle $), T_{s}$

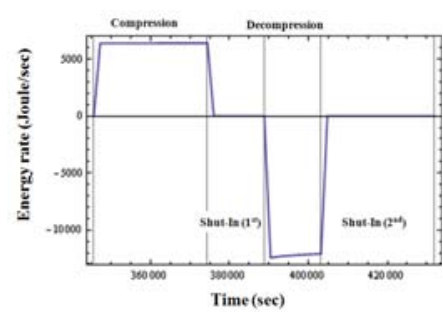

(1) rate of energy due to air injection and production $\left(5^{\text {th }}\right.$ cycle),

$$
\Delta E_{m}+\Delta W_{m}
$$

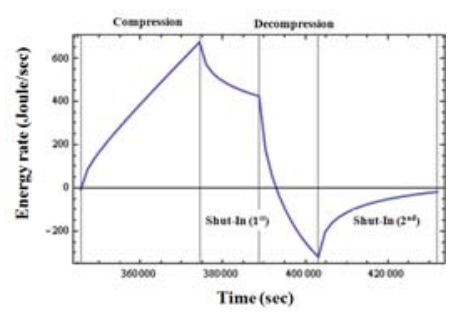

(m) energy loss rate due to air leakage,

$$
\Delta E_{l}+\Delta W_{l}
$$

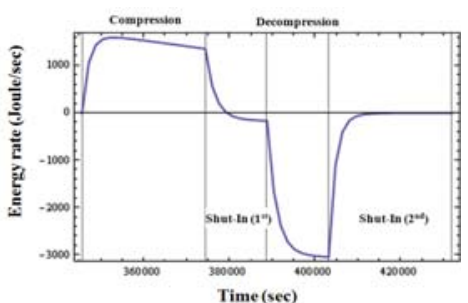

(n) energy loss rate due to heat conduction ( $5^{\text {th }}$ cycle $), \Delta Q_{c}$

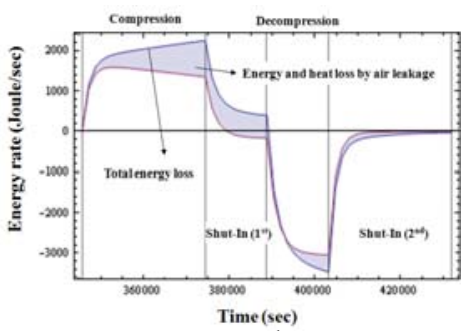

(o) total energy loss ( $5^{\text {th }}$ cycle $),(n)+(i)$

Figure 19. Energy balance terms in the leaky lining case. 


\section{DISCLAIMER}

This document was prepared as an account of work sponsored by the United States Government. While this document is believed to contain correct information, neither the United States Government nor any agency thereof, nor The Regents of the University of California, nor any of their employees, makes any warranty, express or implied, or assumes any legal responsibility for the accuracy, completeness, or usefulness of any information, apparatus, product, or process disclosed, or represents that its use would not infringe privately owned rights. Reference herein to any specific commercial product, process, or service by its trade name, trademark, manufacturer, or otherwise, does not necessarily constitute or imply its endorsement, recommendation, or favoring by the United States Government or any agency thereof, or The Regents of the University of California. The views and opinions of authors expressed herein do not necessarily state or reflect those of the United States Government or any agency thereof or The Regents of the University of California.

Ernest Orlando Lawrence Berkeley National Laboratory is an equal opportunity employer. 